Canadian Journal of Fisheries and Aquatic Sciences

Canadian

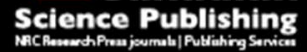

Journal canadien des sciences halieutiques et aquatiques

\title{
Roles of spatial scale in quantifying stock-recruitment relationships for American lobsters in the inshore Gulf of Maine
}

\begin{tabular}{|r|l|}
\hline Journal: & Canadian Journal of Fisheries and Aquatic Sciences \\
\hline Manuscript ID & cjfas-2015-0018.R1 \\
\hline Manuscript Type: & Article \\
\hline Complete List of Authors: & $\begin{array}{l}\text { Chang, Jui-Han; University of Maine, School of Marine Sciences } \\
\text { Chen, Yong; University of Maine, School of Marine Sciences } \\
\text { Halteman, William; University of Maine, Department of Mathematics and } \\
\text { Statistics } \\
\text { Wilson, Carl; Maine Department of Marine Resources, }\end{array}$ \\
\hline Keyword: & $\begin{array}{l}\text { spatial scale, stock-recruitment model, Bayesian, Homarus americanus, } \\
\text { Gulf of Maine }\end{array}$ \\
\hline \multicolumn{2}{|c}{} \\
\hline
\end{tabular}

SCHOLARONE

Manuscripts 
1 Roles of spatial scale in quantifying stock-recruitment relationships for American

2 lobsters in the inshore Gulf of Maine

3

4 Jui-Han Chang ${ }^{1, *}$, Yong Chen ${ }^{1}$, William Halteman ${ }^{2}$, and Carl Wilson ${ }^{1,3}$

5

$6{ }^{1}$ School of Marine Sciences, University of Maine, Orono, ME 04469, USA

$7 \quad{ }^{2}$ Department of Mathematics and Statistics, University of Maine, Orono, ME 04469, USA

$8 \quad{ }^{3}$ Maine Department of Marine Resources, Boothbay Harbor, ME 04538

$9 *$ Corresponding author, juihan.chang@maine.edu 


\section{Abstract}

11 It is well known in ecological studies that the choice of spatial scale can influence the

12 possibility of detecting ecological patterns and the type of patterns observed. However, this has

13 rarely been evaluated for fish stock-recruitment (SR) dynamics. Inappropriate scales may

14 result in failure to identify possible stock-recruitment relationships, especially for species with

15 complicated life history and stock structure and locally generated recruitment. Using American

16 lobster in the Gulf of Maine (GOM) as an example, we tested the hypotheses that the SR

17 relationship is detectable only at certain spatial scales and the functional SR relationships vary

18 with spatial scales. We estimated the SR relationship separately for American lobster in the

19 eastern and western GOM, which have strongly differing oceanographic conditions that may

20 result in different suitable spatial scale and SR dynamics for lobster. We analyzed data of 11

21 different spatial scales using a Bayesian method. The model fit and performances in the

22 posterior predictive assessment for the SR models were convexly related to the spatial scales.

23 The functional SR relationships differed for different spatial scale. The SR parameter estimates

24 are negatively or concavely related to the spatial scale. The best model was found at medium

25 spatial scale for both the eastern and western GOM and the scale differed between the eastern

26 and western GOM, suggesting that optimal spatial scale might be process-related. We

27 demonstrated that the choice of spatial scale directly affected the possibility of identifying the 
28 SR relationship, the estimation of SR parameters, the type of SR relationships and the

29 predictive abilities of the SR models.

30 Key words: spatial scale, stock-recruitment model, Bayesian, Homarus americanus, Gulf of

31 Maine

32 


\section{Introduction}

34 Patterns and scales have long been recognized as two of the most important issues in ecological

35 studies (Levin 1992; Schneider 2001). Although often oversimplified, prevalent ways to make

36 data interpretations and predictions in ecological studies are often based on finding and

37 quantifying patterns in observed data. This results in a tendency to accept data at any spatial

38 scale as appropriate for testing a hypothesis, as long as the analysis is based on data with large

39 sample sizes and results in significant patterns (Rahbek 2005). However, mechanisms that

40 regulate patterns often operate nonlinearly at disparate spatial scales (Pineda et al. 2009).

41 Subject to such complexities, patterns may be different across scales of observations (Chase

42 and Leibold 2002; Rahbek 2005). It is also possible that patterns observed at one scale may not

43 be observable or predictive at other scales. The choice of spatial scale could alter the results of

44 any given analysis (Rahbek 2005). For this reason determining a suitable spatial scale is critical

45 in ecological studies.

46 The spatial scale effects include the extend, which refers to the boundary of the study area,

47 and the grain size, which refers to data resolution (Turner et al. 1989; Rahbek 2005).

48 Information would be lost if the spatial scale of data is too coarse (Turner et al. 1989;

49 Henderson-Sellers et al. 1985; Meentemeyer and Box 1987), whereas a too-fine spatial scale

50 may lead to large random noise and mask patterns in the data. Thus, the key is to analyze data at

51 an appropriate scale to reduce uncertainties in estimates, yet produce rich patterns that are 
52 appropriate to the local ecological processes.

53 Spatial scale issues have been well recognized in studies of patterns of species richness

54 and diversity (Levin 1992; Schneider 2001; Chase and Liebold 2002; Rahbek 2005). For

55 example, the relationship between primary productivity and species diversity was

56 dome-shaped when data were analyzed at a local spatial scale with small grain sizes but

57 positively linear at a regional scale with large grain sizes (Chase and Leibold 2002).

58 Relationships between altitude and species richness vary with the length of the gradient

59 surveyed: dome-shaped relationships were most frequently observed when analyzing the data

60 at small local scales and the relationships disappeared at large regional scales (Rahbek 2005).

61 In marine ecosystems, the spatial scale issues have been considered in studies of population

62 connectivity and recruitment variability, which are important for understanding marine

63 population dynamics and ecosystem resilience (Caselle and Warner 1996; Myers et al. 1997;

64 Cowen et al. 2006; Steneck 2006; Xue et al. 2008; Incze et al. 2010). For example, Myers et al.

65 (1997) concluded that the spatial scale of recruitment correlations for marine species is

66 approximately $500 \mathrm{~km}$ (11 fish species). Spatial scale of population connectivity is roughly 10

67 to $100 \mathrm{~km}$ depending on fish species (Cowen et al. 2006). However, these concepts have not

68 been incorporated into studies of fish stock-recruitment (SR) dynamics, which is critical in

69 fisheries management (Hilborn and Walters 1992). 

Stock-recruitment relationships with or without linkages with environment are generally

71 difficult to quantify for marine populations (Hilborn and Walters 1992). Various factors,

72 including measurement and process errors, complex biological processes, highly varied

73 survival rates of pre-recruits, and non-stationary environment, tend to mask the relationships

74 (Hilborn and Walters 1992; Myers et al. 1996; Needle 2001). Moreover, factors such as pelagic

75 larval duration, larval behavior, adult spawning strategy, predation, food availability, and

76 circulation that regulate the recruitment dynamics often operate at differing spatial scales

77 (Cowen et al. 2006). The spatial scale suitable for estimating the SR relationship should be the

78 scale at which local recruitment can be self-sustained over the natural ranges of interactions of

79 all the biological and ecological processes. Thus, choices of spatial scale may influence the

80 possibility of detecting the SR patterns and the type of SR patterns observed.

81 American lobster support one of the most valuable fisheries in the USA with exvessel

82 revenues of $\$ 401$ million during 2010 (ASMFC 2009). At least $80 \%$ of commercial catch is

83 from inshore waters of the Gulf of Maine (GOM; ASMFC 2009). The landings consist largely

84 of lobster newly molted into the legal size, making it a recruitment fishery (ASMFC 2009). The

85 SR relationship for the American lobster is not well understood.

86 The American lobster has three planktonic larval stages and one planktonic post-larval

87 stage that is morphologically similar to the adult body form. The larvae stay in the water

88 column for roughly15 to 20 days (ASMFC 1997). Several days after molting to the post-larval 
89 stage, the postlarvae start to settle and become young-of-year (YOY) lobster $(\sim 10 \mathrm{~mm}$ carapace

90 length [CL]; Cobb et al. 1989). Juveniles and new fisheries recruits are mainly distributed

91 throughout the inshore waters (at depth $<50 \mathrm{~m}$ ). After the juveniles become sexually mature

92 (around $60 \mathrm{~mm} \mathrm{CL}$ ), they tend to move towards deeper waters (Lawton and Lavalli 1995).

93 Different life history stages tend to have different ecological characteristics and habitat

94 requirements (Aiken and Waddy 1986; Fogarty and Idoine 1986; Mercaldo-Allen and Kuropat 95 1994; ASMFC 2009).

96 Processes that determine lobster recruitment dynamics, such as temperature, salinity,

97 substrates, predation, and food supplies, vary across life history stages that are found in

98 different habitats. The effect of these processes is likely to operate at different spatial scales.

99 Moreover, Xue et al. (2008) and Incze et al. (2010) indicated considerable potential that a

100 significant amount of lobster recruitment in the coastal GOM is derived from local sources.

101 Whether the recruitment is a local event or global phenomena could influence the possibility of

102 detecting the SR relationships at a stock level. Thus, the spatial scale of effective biological

103 processes may be critical in analyzing the SR relationships. However, this issue has not yet

104 been considered in estimating the lobster SR relationships.

105 The characteristics of complicated life history stages and locally generated recruitments

106 may be the reasons why only the relationships for adjacent or nearly adjacent life history stages

107 in relatively small regions were found for American lobsters. Positive relationships were found 
108 for postlarvae and YOY lobster and between settlers and lobsters of nearly legal size (Incze et

109 al. 1997; Wahle et al. 2004). Asymptotic relationships were found for the final larval stage and

110 fishery recruitment in a relatively small region (Fogarty and Idoine 1986; Ennis and Fogarty

111 1997). No relationships have been identified across multiple life history stages and at the stock

112 level over large geographic areas.

113 Mechanisms that regulate the SR relationship for American lobster may operate

114 differently in different regions of the GOM because of the large differences in physical

115 environment within the stock boundary. The GOM has a cyclonic flow of the interior regions

116 and a coastal current system (Gulf of Maine Coastal Current; GMCC) over shallow coastal

117 areas opposing the mean wind stress. The mean flow of GMCC is southwestward from Grand

118 Manan Island to Massachusetts Bay, due to fresh-water inflows during the spring and summer

119 (Brooks 1985). The GMCC creates strong northeast to southwest gradients in temperature,

120 salinity, and productivity in the coastal GOM (Lynch et al. 1997; Pettigrew et al. 1998) and is

121 prominent in the summer when larvae recruits are in the water column. The GMCC consists of

1222 major branches: the Eastern Maine Coastal Current (EMCC) and the Western Maine Coastal

123 Current (WMCC) (Fig. 1). The EMCC constitutes cold, deep, high-nutrient Labrador Current

124 water and fresh water input from St John River and extends between Grand Manan Island and

125 Penobscot Bay. It is generally the most consistent and vigorous part of the GMCC (Xue et al.

126 2008). The EMCC bifurcates in the vicinity of Penobscot Bay where a portion moves offshore 
127 to the centre of the Gulf and the rest continues along the coast and combines with the outflow

128 from Maine rivers (including the Kennebec, Androscoggin, Penobscot, Merrimack and St John

129 rivers) to constitute the WMCC (Pettigrew et al. 2005).

130 The degree of continuity of EMCC to WMCC varies dramatically each year (Pettigrew et

131 al. 2005), likely a result of differing strength of convective mixing in the winter and wind

132 forcing (Xue et al. 2008). The freshwater plume that strengthens the southwestward flow also

133 varies with a tendency to increase in recent years (2003 to 2010) compared to the years 1998 to

1342002 (Churchill et al. 2005; McManus et al. 2014). The combination of the two sources of

135 variation causes the WMCC to be highly variable. Manning et al. (2009) summarized the data

136 of 227 satellite-tracked drifters deployed in the GOM during spring and summer from 1988 to

1372007 and found that the EMCC is a relatively steady, flow-through system, while WMCC has

138 more variable branching pathways. Circulation has strong influences on the distribution of

139 lobster recruitment, at least for the first 3 planktonic stages (Xue et al. 2008; Incze et al. 2010).

140 Due to large differences in the EMCC and WMCC, the effects of circulation on the SR

141 relationship should be operated at different spatial scales for the eastern and western GOM.

142 We tested the following three hypotheses: (1) the SR relationship for American lobster in

143 the GOM is detectable only at certain spatial scales; (2) the functional SR relationships vary

144 with spatial scales; and (3) the results in (1) and (2) are different because the mechanisms that

145 regulate recruitment dynamics differ between the eastern and western GOM. To test our 
146 hypotheses, we first quantify the SR relationships for the American lobster in the GOM using

147 different spatial scales of data. We then evaluate the performance of the models of different

148 spatial scales and the potential effects of misuse of spatial scale in predicting lobster

149 recruitment, particularly under low and high recruitment situations. The analyses are done

150 separately for the eastern (lobster management zones A to C) and western GOM (lobster

151 management zones D to G and the coastal New Hampshire area) where the coastal currents are

152 different in this magnitude and consistency (Fig. 1). We then discuss the role of spatial scale in

153 estimating the SR relationship for American lobster in the GOM. 
154

155

156

157

158

159

160

161

162

163

164

165

166

167

168

169

170

171

172

\section{Material and Methods}

\section{Data}

Recruitment is defined as density of young of year (YOY) lobsters during the settlement season in the late summer to early fall. The recruitment data are collected by a settlement survey conducted by Bigelow Laboratory for Ocean Sciences (years 2002 to 2005) and Maine DMR (years 2005 to 2008). The YOY lobsters are collected by a suction sampler in cobble-boulder lobster nursery habitats at fixed stations along the coastal northeast United States and Atlantic Canada (Wahle and Incze 1997; Wahle et al. 2004; Wahle et al. 2013). Number, size and sex of YOY and juveniles lobsters are recorded during the survey and the average density per $\mathrm{m}^{2}$ is estimated for each sampled location. Recruitment data are available for the seven lobster management zones including 42 sites in the coastal Maine area (Fig. 2).

Spawning stock size is defined as the number of female lobsters measured in the fall (October to December) with $\mathrm{CL}>60 \mathrm{~mm}$, which is the minimum size at maturity for the GOM stock (ASMFC 2009). The mean spawning stock size for each year and location where recruitment data were collected was predicted using a two-stage GAM model which was developed by Chang et al. 2010 using data collected by the Maine DMR inshore trawl survey program from 2000 to 2006 . A detailed description of the survey and model development can be found in Chang et al. (2010). Eight environmental and spatial variables were considered in the GAM model including temperature, salinity, latitude, longitude, depth, distance offshore, 
173 and two sediment-related variables. The bottom temperature and salinity used for model

174 prediction were obtained from the GoMOOS circulation nowcast/forecast system (Xue et al.

175 2005). The spawning stock sizes were estimated at 11 different spatial scales: $0.125,0.25,0.5$,

$1761,2,4,8,16,32,64$, and $128 \mathrm{~km}$ grid diameter (a geometric series with a common ratio of 2).

177 The estimates of spawning stock size for small spatial scales preserved local information,

178 whereas the estimates of large spatial scales represented the mean condition of the whole study

179 area. Examples of spatial distribution of the estimated spawning stock size and surveyed

180 recruitment data are in Fig. 2. We analyzed the SR data from 2002 to 2008 for the eastern and

181 western GOM (Fig. 2). Eleven different spatial scales and two different regions result in 22 sets

182 of SR data being analyzed.

183 Model development

184 The Beverton-Holt (Beverton and Holt 1957) (B-H) and Ricker model (Ricker, 1954) with

185 multiplicative lognormal errors were used to estimate the SR relationship for the 11 data sets

186 grouped by different spatial scales for each region. The B-H model can be written as

$187 \quad R_{t, g}=\frac{S_{t, g}}{\alpha+\beta S_{t, g}} e^{\varepsilon_{t, g}}$

188 where $R_{t, g}$ is the recruitment at time $t$ grid $g, S_{t, g}$ is the spawning stock size that generate the

189 recruitment measured at time $t$ grid $g, \alpha$ determines the steepness at origin and $\beta$

190 determines asymptotic limits $(1 / \beta)$ of the curve (recruitment reaches the asymptotic limits

191 faster when $\beta$ is smaller), and $\varepsilon_{t, g}$ are the random errors that followed $N\left(0, \sigma^{2}\right)$. The B-H 
192 model assumes that density dependent mortality rate is related to cohort size and therefore it

193 appears an asymptotic-shaped curve. The Ricker model can be written as

$194 R_{t, g}=\alpha S_{t, g} e^{-\beta S_{t, g}+\varepsilon_{t, g}}$

195 where $\alpha$ determines the recruits per spawner when $S$ is low and $\beta$ determines the rate of

196 decrease of recruits per spawner as $S$ increases. The density dependent mortality rate of the

197 Ricker model is assumed to be related to total stock size and therefore the Ricker model

198 exhibits a decline in recruitment levels at higher spawning stock size.

199 When the spatial scale used to group the spawning stock size is large enough, repeated

200 recruitment measurements occurred within the grids (Fig. 2). We included a random effect in

201 both equations 1 and 2 to account for the variation of the repeated measurements

202

$R_{t, g, i}=\frac{S_{t, g, i}}{\alpha+\beta S_{t, g, i}} e^{v_{t, g}+\varepsilon_{t, g, i}}$

203

$R_{t, g, i}=\alpha S_{t, g, i} e^{-\beta S_{t, g, i}+v_{t, g}+\varepsilon_{t, g, i}}$

204 where $v_{t, g}$ is the random effect at time $t$ grid $g$ and $\varepsilon_{t, g, i}$ is the individual-specific error and

205 both $v_{t, g}$ and $\varepsilon_{t, g, i}$ follows normal distribution. We estimated the parameters from the $\log$

206 form of equations 1-4.

207 We used Bayesian method to estimate the SR relationship because it is a methodology for

208 capturing variability and risks resulting from the uncertainties inherent to a fishery (Punt and

209 Hilborn 1997). The models were run with 20,000 burn-in iterations, followed by 100,000

210 iterations for each of the three Markov chains. The sequences were thinned by keeping every 
$211100^{\text {th }}$ iteration to draw quasi-independent samples from the autocorrelated chains and form the

212 posterior distribution for each parameter. A total of 3,000 samples were drawn for each dataset.

213 Convergence of the parameters was examined using a potential scale reduction factor $\hat{R}_{f}$,

214 which is used to indicate possible reduction of variance parameter of posterior distribution if

215 the simulations continued (Gelman et al. 2004),

$216 \quad \hat{R}_{f}=\sqrt{\frac{\operatorname{var}(\psi \mid R)}{W}}$

217 where $\operatorname{var}(\psi \mid R)=\frac{n-1}{n} W+\frac{B}{n}, W$ is the within-sequence variance, $B$ is the

218 between-sequence variance, $n$ is the sample size for each sequence (after discarding the first

219 half of the simulations), and $\operatorname{var}(\psi \mid R)$ is the marginal posterior variance of the estimate. The

220 within-sequence variance should be smaller than the marginal posterior variance because the

221 individual sequence covers only part of the target distribution. If the sequences are stable

222 enough (converged), the two variances should be similar and the factor should be around 1.

223 Parameter estimation was considered to be converged if its $\hat{R}$ value is close to 1 and below

2241.1 (Gelman et al. 2004). The models were executed in WinBUGS 1.4.3 (Lunn et al. 2000) and

225 convergence evaluations were carried out in R 3.0.2 (R Core Team 2013).

226 Prior distribution

227 The subjective choice of prior distributions receives one of the biggest criticisms for using

228 Bayesian approach (Michielsens and McAllister 2004), although this could be an advantage

229 when expert knowledge and information of the parameters are available. In order to be fair in 
230 comparing data sets of different scales, we assumed noninformative prior distributions for all

231 the SR parameters to make sure that the amount of information each data set received was

232 approximately the same. An intuitive form of noninformative prior distribution might be a

233 uniform distribution for which the parameter is estimated within a range of values with equal

234 probabilities being selected. However, model parameterization determines whether the

235 uniform prior distribution is truly noninformative. Jeffrey's prior, on the other hand, is a type of

236 noninformative prior that is derived using Fisher information (square root of the determinant of

237 the information matrix) and thus is invariant under parameterization choices (Robert et al.

238 2009). The Jeffrey’s priors for standard Ricker and Beverton-Holt models were derived by

239 Millar (2002) and were used in this study. The Jeffrey's prior for the Ricker model is

$240 \pi(\alpha, \beta) \propto \frac{1}{\alpha}, \alpha>0, \beta \geq 0$

241 and for the Beverton-Holt model is

$242 \pi(\alpha, \beta) \propto \frac{\operatorname{sd}(y(\beta))}{\alpha}, \alpha>0, \beta \geq 0$

243 where $y_{i}(\beta)=\frac{S_{i}}{1+\beta S_{i}}, i=1 \ldots n$

244 and $\operatorname{sd}(y(\beta))$ is the standard deviation of the $y_{i}(\beta)$. For the variance parameter of the

245 random effects $v_{t, g}$, we used the uniform prior density as suggested by Gelman (2006).

246 Since we have enough data for both east $(n=84)$ and west region $(n=187)$, we should be able to

247 estimate the variance of $\varepsilon_{t, g, i}$ with any reasonable noninformative prior distribution (Gelman

248 2006). We chose the uniform prior density for the variance parameter of the $\varepsilon_{t, g, i}$. 


\section{Model evaluation and validation}

250 The following three methods can be used to evaluate Bayesian models (Gelman et al. 1996): (1)

251 evaluating sensitivity of prior distributions; (2) checking how well the model fits, and (3)

252 evaluating whether posterior inferences are reasonable.

253 We conducted sensitivity analysis to evaluate the influence of prior distributions on the

254 posteriors by assuming uniform priors with large upper bounds for parameters $\alpha$ and $\beta$, and

255 half-Cauchy priors for the variance of $v$ and $\varepsilon$. We changed prior distribution for one

256 parameter each time. We compared the results of posterior predictive assessment of these

257 models estimated using different priors to evaluate the sensitivity of prior distributions.

258 The goodness-of-fit for different types of SR models and models constructed using data of

259 different spatial scales was evaluated using model deviance:

$260 \mathrm{D}(\theta)=-2 \log (\mathrm{L}(R \mid \alpha, \beta))$

261 where $\mathrm{L}(R \mid \alpha, \beta)$ is the likelihood function. The deviance was calculated for each iteration. A

262 lower deviance value indicates a better model fit.

263

Checking the posterior inference is crucial to Bayesian statistical analysis because the

264

analysis is conditional on the whole probability model (priors and likelihood functions). This

265

can lead to biased or unrealistic results when the model is far from plausible (Meng 1994;

266 Gelman et al. 1996). We checked the posterior inferences by comparing data simulated from 
268 replicate the observed data with reasonable probabilities (Gelman et al. 1996). The posterior

269 predictive distribution is denoted as

$270 \quad \mathrm{p}\left(R^{r e p} \mid R, S R\right)=\iint \mathrm{p}\left(R^{r e p} \mid \alpha, \beta, S R\right) \mathrm{p}(\alpha, \beta \mid R, S R) d(\alpha) d(\beta)$

271 where SR is the stock-recruitment model, $R^{\text {rep }}$ is the replicated data that could have been

272 observed if we redo the survey during the time period and location that $R$ was observed, based

273 on the current model assumptions and the parameter estimates. The simulation of $R^{\text {rep }}$ started

274 with drawing a set of parameters $\alpha_{J}$ and $\beta_{J}, J=1, \ldots, N$, from the posterior distribution. In

275 this study we drew 1,000 pairs of parameters from the posterior distribution. Given the

276 parameter sets, we drew a simulated set of replicated data $R_{J}^{\text {rep }}$ from the sampling distribution

$277 \mathrm{p}\left(R_{J}^{r e p} \mid \alpha_{J}, \beta_{J}, S R\right)$. The observed data $R$ and the replicated data $R^{\text {rep }}$ are independent datasets

278 and both represent possible datasets resulting from the given values of $\alpha$ and $\beta$ and the SR

279 model. A large or systematic difference between $R$ and $R^{r e p}$ could be an indication of potential

280 model failure.

281 The comparison of $R$ and $R^{\text {rep }}$ was carried out by a discrepancy measure, which is a sum

282 of squares of standardized residuals of data with respect to their estimated expectations and

283 variances, calculated for both observed and replicated datasets

$284 D\left(R, \alpha_{J}, \beta_{J}\right)=\sum_{j=1}^{n} \frac{\left(R_{j}-\mathrm{E}\left(R \mid \alpha_{J}, \beta_{J}\right)\right)^{2}}{\operatorname{var}\left(R \mid \alpha_{J}, \beta_{J}\right)}$

$285 D\left(R_{J}^{r e p}, \alpha_{J}, \beta_{J}\right)=\sum_{j=1}^{n} \frac{\left(R_{j}^{r e p}-\mathrm{E}\left(R \mid \alpha_{J}, \beta_{J}\right)\right)^{2}}{\operatorname{var}\left(R \mid \alpha_{J}, \beta_{J}\right)}, \quad J=1 \ldots N$ 
286 where $n$ is the sample size for each dataset and $N$ is the number of parameter draws from the

287 posterior distribution. The more overlap between marginal posterior distributions of the

288 observed and predicted discrepancy measures, the better the model could replicate the

289 observed data. We used overlap coefficient, defined below, to measure the overlap between the

290 two marginal posterior distributions

291 overlap coefficient $=\frac{D(R, \alpha, \beta) \cap D\left(R^{\text {rep }}, \alpha, \beta\right)}{\min \left(D(R, \alpha, \beta), D\left(R^{\text {rep }}, \alpha, \beta\right)\right)}$

292 The overlap coefficient is between 0 and 1 depending on the degree of overlapping, and it is 1 if

293 the two distributions are completely overlapped and 0 otherwise.

294 The discrepancy measure is analogous to the classical goodness-of-fit measures. If the

295 observed data follow normal distribution or are approximately normal, given $\alpha$ and $\beta$ the

296 discrepancy measure has a (or an approximate) $\chi_{n}^{2}$ distribution. A classical p-value based on

297 D can be calculated as

$298 \quad \mathrm{p}_{\mathrm{c}}=\iint \mathrm{p}\left(\chi_{n}^{2} \geq D(R, \alpha, \beta)\right) \mathrm{p}(\alpha, \beta \mid R, S R) d(\alpha) d(\beta)$

299

$\mathrm{p}_{\mathrm{c}}^{\text {rep }}=\iint \mathrm{p}\left(\chi_{n}^{2} \geq D\left(R^{\text {rep }}, \alpha, \beta\right)\right) \mathrm{p}(\alpha, \beta \mid R, S R) d(\alpha) d(\beta)$

300 where $\chi_{n}^{2}$ is the chi-squared random variable with $n$ degree of freedom. However, given the

301 complexity of our models, the degree of freedom for the chi-square distribution is hard to

302 estimate. Rather than assuming a $\chi^{2}$ distribution and calculating the classical p-values, we

303 used the Monte Carlo simulations to compute a Bayesian p-value (without any distributional

304 assumption), which is defined as the probability that the replicated data are more extreme than 
305 the observed data given the posterior distribution of $\alpha, \beta$ and the posterior predictive

306 distribution of $R^{\text {rep }}$

307

$\mathrm{p}_{\mathrm{B}}=\iiint \mathrm{I}_{D\left(R^{r e p}, \alpha, \beta\right) \geq D(R, \alpha, \beta)} \mathrm{p}\left(R^{r e p} \mid \alpha, \beta, S R\right) \mathrm{p}(\alpha, \beta \mid R, S R) d\left(R^{r e p}\right) d(\alpha) d(\beta)$

308 where I is the indicator function. If the model can replicate the observed data well, the

309 estimated Bayesian p-value should be close to 0.5 .

310 We specifically examined potential implications of SR models of different spatial scales

311 on predicting low ( $\leq 25$ th percentile) and high ( $\geq 75$ th percentile) recruitment since these are

312 most important to fishery stock assessments. This is evaluated by comparing deviances

313 summing over only the low and high recruitment

314

$D_{25}\left(R_{J}, \alpha_{J}, \beta_{J}\right)=\sum_{j=1}^{n-k} \frac{\left(R_{(j)}-\mathrm{E}\left(R \mid \alpha_{J}, \beta_{J}\right)\right)^{2}}{\operatorname{var}\left(R \mid \alpha_{J}, \beta_{J}\right)}$

$315 D_{75}\left(R_{J}, \alpha_{J}, \beta_{J}\right)=\sum_{j=k}^{n} \frac{\left(R_{(j)}-\mathrm{E}\left(R \mid \alpha_{J}, \beta_{J}\right)\right)^{2}}{\operatorname{var}\left(R \mid \alpha_{J}, \beta_{J}\right)}, J=1 \ldots N$

316 where $\mathrm{k}$ is the number of samples that exceed the 25 th percentile or below 75 th percentile. 


\section{Results}

$318 \quad$ Parameter estimates

319 The $\hat{R}_{f}$ for the $\alpha$ and $\beta$ parameters of the Ricker and B-H models for the 22 data sets

320 grouped in different spatial scales to mimic observing SSB and recruitment in different spatial

321 scales ranged from 1 to 1.09 , suggesting that all the parameters estimates were converged

322 (Table 1).

323 The estimated parameters are not random across different spatial scales used to aggregate

324 the data (Fig. 3; Table 1). For the B-H model, the parameter estimates decreased with

325 increasing spatial scales (Fig. 3; Table 1). For the Ricker model, the parameter estimates are

326 concavely related to spatial scale (Fig. 3; Table 1).

327 Model fitting

328 The model deviances varied non-randomly with models constructed using data of different

329 spatial scales for both Ricker and B-H models and the two regions (Fig. 4). For the models

330 developed based on data of small spatial scales for both regions, the deviances were relatively

331 high, suggesting a poor model fit (Fig. 4). Model deviances started to decrease with spatial

332 scales after spatial scales reached $4 \mathrm{~km}$ for the eastern GOM and $2 \mathrm{~km}$ for the western GOM

333 with large variations (Fig. 4). The best model fit (i.e., model with the lowest deviance) was

334 found at the spatial scale of $8 \mathrm{~km}$ and $2 \mathrm{~km}$ for the eastern and western GOM, respectively, 335 indicating the existence of optimal spatial scale for data analysis (of all the spatial scales tested; 
336 Fig. 4). The variance of the deviance at the optimal spatial scales were larger compared to the

337 other spatial scale scenarios for both the regions (Fig. 4). After exceeding the optimal spatial

338 scale, model fitting deteriorated suddenly for the eastern region. For the west region, model

339 fitting deteriorated gradually after spatial scale of $32 \mathrm{~km}$ (Fig. 4). The range of spatial scales

340 with low deviances (i.e., good goodness-of-fit) was from $2 \mathrm{~km}$ to $128 \mathrm{~km}$ for the western GOM,

341 which is much wider than the eastern GOM where the low deviances only occurred at spatial

342 scales of $4 \mathrm{~km}$ and $8 \mathrm{~km}$ (Fig. 4). The existence of the trend of model fits with respect to spatial

343 scale supports our hypotheses (1) and (3) outlined early.

344 The performance of the B-H model was superior to the Ricker model at smaller spatial

345 scales for both the regions (Fig. 4). When the spatial scale was larger than $4 \mathrm{~km}$ for the eastern

346 GOM and $16 \mathrm{~km}$ for the western GOM, the Ricker model fit consistently had a better fit than

347 the B-H model except for the spatial scale of $16 \mathrm{~km}$ for the eastern GOM model (Fig. 4). At

348 optimal spatial scales, Ricker model was a better model for both the regions (Fig. 4). These

349 results suggest that the choice of spatial scale could influence the type of SR relationship being

350 observed. This result supports our hypotheses (2) and (3). The regional difference in the

351 hypothesis (2) was less obvious than that in the hypothesis (3).

\section{Model predictive assessment}

353 The observed data were compared to the data simulated from the posterior predictive

354 distributions. The Bayesian p-values and the marginal posterior distributions for different 
355 levels of recruitment were presented in Fig. 5 and Table 2. The predictive assessment results

356 showed that if all levels of the predicted recruitments were evaluated simultaneously, all the

357 models could replicate the observed data well (overlap coefficient close to 1 and Bayesian

$358 \mathrm{p}$-value close to 0.5 ) except for the Ricker model based on data of $0.125 \mathrm{~km}$ spatial scale for the

359 western GOM (Fig. 5; Table 2).

360 However, when the model performances were evaluated by levels of recruitment, the

361 model performances were different by spatial scales, regions, and model types. The

362 recruitments lower than 25 th percentile and higher than 75 th percentile were better replicated

363 by the eastern GOM models compared to the western GOM models and for the Ricker models

364 compared to the B-H models (Fig. 5; Table 2). Both the eastern GOM models and the Ricker

365 models shown had their Bayesian p-values closer to 0.5 and higher percent overlaps of the

366 marginal posterior distributions (Table 2).

367 The low and high recruitments were well replicated by models around optimal spatial

368 scale (Fig.5; Table 2). For the rest of the models, even though their performances of replicating

369 all levels of recruitment were similar to the models of optimal spatial scales, these models

370 could not replicate the low and high recruitments well (Fig. 5; Table 2). The p-values for low

371 and high recruitment were below and above 0.5 at small spatial scales, gradually converged to

3720.5 as spatial scales increased to the optimal size (Table 2). After exceeding the optimal spatial

373 scale, the p-value was diverged from 0.5 again (Table 2). Similar results could be found for the 
374 marginal posterior distributions: the observed and predicted distributions were barely

375 overlapped at small spatial scales, but gradually overlapped when approaching optimal spatial

376 scale (overlap coefficients close to 0.9); and diverged from each other again after exceeding the

377 optimal spatial scale (Fig. 5; Table 2).

378 The western GOM, however, was an exception. None of the B-H models could predict the

379 low and high recruitments well (Fig.5; Table 2). For the low recruitments, at optimal spatial

380 scales, the p-values were highest but still less than 0.1 ; and the overlap coefficients of marginal

381 posterior distributions were highest but only around 0.3 (Fig.5; Table 2). For the high

382 recruitments, all the p-values are lower than 0.01 and overlap coefficients are lower than 0.15 ,

383 suggesting a very poor model performance. The Ricker models could not well predict the low

384 recruitments at all scales, but performed well for the high recruitments around optimal spatial 385 scale.

\section{Sensitivity of prior distribution}

387 We compared the results of posterior predictive assessments of models using different prior

388 distributions for parameters $\alpha, \beta, v$. and $\varepsilon$. The differences in overlap coefficients are

389 mostly less than 0.1 , suggesting that the posteriors are not sensitive to the prior distributions.

\section{Stock-recruitment relationship}

391 The Ricker and B-H SR relationships for the American lobster for the eastern and western

392 GOM using data aggregated with different spatial scales were presented in Fig. 6. The 
393 relationship differed greatly when data were grouped with different spatial scales (Fig. 6).

394 When the spatial scale was too small, most of the data points were clustered at origin with large

395 variations and therefore the recruitment was almost independent of spawning stock size (Fig.

396 6). When the spatial scale was too large, data points spread across different values of the

397 spawning stock size but with large variations and the relationship could not be well determined

398 (Fig. 6). The relationship between spawning stock size and recruitment was discovered at

399 optimal spatial scale (Fig. 6). The data exhibited a clear Ricker type SR relationship for the east

400 region (Fig. 6). For the west region, the data still revealed a Ricker type relationship but the

401 recruitment declined at higher spawning stock size until the largest spawning stock size (Fig.

$4026)$.

403 


\section{Discussion}

405 We estimated the SR relationship for American lobsters in the GOM using the same SR

406 data but grouped in different spatial scales. We demonstrated that the choice of spatial scale is

407 critical in quantifying the SR relationships. The spatial scale of data directly affected the

408 possibility of identifying the SR relationship, the estimation of SR parameters, the type of SR

409 relationships and the predictive abilities of the SR models. Therefore, the spatial scale has

410 significant influences on the SR data interpretations and the use of SR data for recruitment

411 predictions. The SR model parameter estimates are either negatively or concavely related to the

412 spatial scale of data used to build the model. This result implies that the spatial scale of data

413 used to estimate the SR relationship has systematic influences on the estimations of recruitment.

414 The parameter estimates of B-H models decreased with increasing spatial scales and were

415 lower at the median size spatial scales than other sizes for the Ricker model. The parameter $\alpha$

416 is a location parameter in both the Ricker and B-H models, that is proportional to fecundity

417 (Quinn and Deriso 1999). A decrease in $\alpha$ for both models shifts the entire curve down,

418 which means that the estimated recruitments from the same amount of spawning stock size

419 decrease. Thus, size of the spatial scale has systematic influences on the prediction of stock

420 productivities. The $\beta$ parameter measures the level of density dependence (Hilborn and

421 Walters 1992). A decrease in $\beta$ decreases the rate of decrease of recruitment as spawning

422 stock size increases for the Ricker model and decreases the steepness at origin for the B-H 
423 models. The decrease in $\beta$ has more influences on the estimations of recruitment when the

424 spawning stock size is low for the B-H models and high for the Ricker models. These results

425 have significant implications for fisheries stock assessments since the SR relationship is one of

426 the key functional relationships that determine the dynamics of the target population and

427 reference point estimations (Hilborn and Walters 1992; Quinn and Deriso 1999). The trend in

428 parameter estimates can cause bias in fisheries stock assessment though the bias can be

429 inconsistent over years depending on the temporal stabilities of the mechanism that regulates

430 the relationship.

431 Similar to the parameter estimates, the SR model fits and model performances in the

432 posterior predictive assessment are convexly related to the spatial scale of data used to estimate

433 the SR relationship. The best model was found at median spatial scale for both the eastern and

434 western GOM. The fact that the parameter estimates and model fits are to some extent related

435 to the spatial scale of data implies that the optimal spatial scale modeling the SR relationship

436 does exist and is not an artifact.

437 The spatial scale of data could influence the possibility of discovering the SR relationship

438 for American lobster in the inshore GOM. The SR relationships were detectable only at certain

439 spatial scales. When the spatial scale was smaller than the optimal spatial scale, most of the

440 recruitments were found at low spawning stock sizes with a few exceptions and the data tend to

441 cluster at origin with large variations. The less the data are aggregated, the more the local 
442 information is preserved. However, if the scale is smaller than the spatial scale at which the SR

443 process operates, the information contains too much random noise that could mask the

444 underlying relationships.

445 When the spatial scale is larger than the optimal spatial scale, recruitments were found at

446 all levels of the spawning stock size but with large variations. If the data are largely aggregated,

447 they are more a representation of the average regional or global conditions rather than the local

448 dynamics. If the scale is larger than the spatial scale at which the SR process operates, the

449 information is too general and the SR relationships could not be clearly revealed. This is

450 especially applicable to the American lobsters in the inshore GOM area because their

451 recruitments were found to be largely generated locally (Xue et al. 2008; Incze et al. 2010).

452 The 2002 to 2008 data used in this analysis reflect lobster stock conditions at historic high

453 abundance (ASMFC 2009). Therefore, we may not have enough information to estimate SR

454 relationships at low stock sizes (near origins) when the spatial scale of data is large (there are

455 still data at low stock sizes when spatial scale of data is small). This is likely to affect the size

456 and range of optimal spatial scale for SR analysis. If the data used in SR analysis include stock

457 conditions at historic low abundance, the SR relationships might be better estimated at large

458 spatial scales and the size of optimal spatial scale and range of spatial scales with good model

459 fit might increase. 
461 related to the general circulation of the inshore GOM. For the eastern GOM, where the current

462 is more steady and consistent, the range of the spatial scales with relatively good model fits is

463 smaller $(4-8 \mathrm{~km})$. The relationship can only be found at specific spatial scales and the SR

464 relationship is much more defined. In the western GOM, where the current is more variable and

465 less constrained; the range of good model fits is wider $(2-128 \mathrm{~km})$. The spatial scales to

466 discover the SR relationship is less specific and the relationship is less defined. The differences

467 of the SR model results in the eastern and western GOM supported our hypothesis that the

spatial scale of data used to build the model is related to the underlying mechanisms that result

469 in the relationship. Similar results were shown in Incze et al. (2010) study of lobster larvae

470 transport along the coastal GOM that the annual difference in postlarval days and abundances

471 of competent postlarvae occurred primarily in the west region.

472 The performance of the Ricker model is superior to the B-H model for the data of optimal

473 spatial scale and scales larger than $4 \mathrm{~km}$ for the eastern GOM and $16 \mathrm{~km}$ for the western GOM,

474 indicating that density-dependent mechanisms are regulating the population dynamic of

475 American lobster. One of the density-dependent mechanisms discovered for American lobster

476 is cannibalism. This may play an important role in regulating the population size of American

477 lobster due to the depletion of large predatory groundfish and record high lobster population

478 size in recent years (ASMFC 2009; Oppenheim and Wahle 2013). This supports our results of 
479 favoring Ricker type of SR relationship over B-H type. Our results showed that type of SR

480 relationships varies by the spatial scale of data. Thus, misuse of the spatial scale of data to

481 estimate the SR relationship could lead to misinterpretation of population dynamics.

482 We did not include any of the auxiliary variables while estimating the SR relationships for

483 the American lobster in the coastal GOM. Many of the biotic (food, predation, etc.) and abiotic

484 (temperature, current, etc.) variables were demonstrated to have impacts on the recruitment

dynamics but the relative importance of these variables remains unclear (ASMFC 2009). In the

coastal GOM, environmental and physical features differ between the east coast and the west

487 due to variations in physical forces and inputs of multiple water masses. For example, summer

bottom water temperatures are often warmer in the well-mixed EMCC and cooler in the

well-stratified WMCC (Townsend 1991). The dissolved inorganic nutrients are higher in the

490

EMCC but a majority of them were recycled into the WMCC resulting in a higher primary

491

productivity in the western coastal GOM (Townsend 1991). Our analyses were done separately

for the east and the west region. This should take into account some of the differences in the

biotic and abiotic impacts along the coastal GOM. Since these impacts may also affect the

spawning stock, they are likely to be confounded with the effect of spawning stock sizes when the spatial scale is appropriately defined.

Based on the posterior predictive assessment results, we show that there are significant 
498 small or too large, specifically for the low and high spawning stock sizes. "Essentially, all

499

500

501

502

503

504

505

506

507

508

509

510

511

512

513

514 without including the processes themselves in the model could already increase the possibility

515 of defining SR relationship. This study demonstrates that the influences of spatial scale of the

516

models are wrong, but some are useful" (Box and Draper 1987). Our results demonstrated that

the SR model is not as useful when the spatial scale is misspecified. This result has significant

implications to fisheries stock assessment, since the assessment results are usually more

controversial when the spawning stock sizes are at the low or high end.

The spatial scale of fisheries management should be consistent with the spatial scale of

ecological process. It would be possible to come up with a SR model that is useful for the

whole GOM stock for American lobster since the optimal spatial scale for the eastern and

western GOM does not differ greatly. However, the clearer relationship that we found for the

east region might be masked if we model the GOM stock as a whole.

It is impossible (or too costly) to achieve a full mechanistic understanding of SR

relationship by studying all the components and its interactions in the system, although the

knowledge is essential for fully understanding the SR relationship. Without studying

fundamental processes and the interaction between processes that result in the SR relationship,

our approach is relatively simple, yet useful in demonstrating that SR relationship is

process-related. Considering spatial scale of interactions of fundamental processes alone

data in estimating the SR relationship is significant and needs to be carefully considered, 
517 especially for species with locally generated recruitment, complicated life history stages and

518 populations structure, and complex interactions with their environments.

519 Acknowledgements

520 We thank R. Wahle and C. Bergeron for providing the recruitment data and R. Wahle for

521 discovering a major data issue, A. Thomas for editing the manuscript, and three anonymous

522 reviewers for valued comments that improved the manuscript.

523 


\section{References}

525 Aiken, D.E., and Waddy, S.L. 1986. Environmental influence on recruitment of the American

526 lobster, Homarus americanus: a perspective. Can. J. Fish. Aquat. Sci. 43: 2258-2270.

527 ASMFC 2009. American Lobster Stock Assessment Report for Peer Review. Atlantic State

$528 \quad$ Marine Fisheries Commission, Providence, RI.

529 Beverton, R J.H., and Holt, S.J. 1957. On the dynamics of exploited fish populations. Fish.

$530 \quad$ Invest. Ser. II Mar. Fish. G.B. Min. Agric. Fish. Food No. 19.

531 Box, G.E.P., and Draper, N. 1987. Empirical model building and response surfaces. John Wiley

$532 \quad \&$ Sons, New York.

533 Brooks, D.A., 1985. Vernal circulation in the Gulf of Maine. J. Geophys. Res. 90(C3):

$534 \quad 4687-4705$.

535 Caselle, J.E., and Warner, R.R. 1996. Variability in recruitment of coral reef fishes: the

536 importance of habitat at two spatial scales. Ecology, 77: 2488-2504.

537 Chang, J.H., Chen, Y., Holland, D., and Grabowski, J. 2010. Estimating spatial distribution of

538 American lobster Homarus americanus using habitat variables. Mar. Ecol. Prog.

$539 \quad$ Ser. $420: 145-156$.

540 Chase, J.M., and Leibold, M.A. 2002. Spatial scale dictates the productivity-biodiversity

541 relationship. Nature, 416(6879): 427-430.

542 Churchill, J.H., Pettigrew, N.R., and Signell, R.P., 2005. Structure and variability of the 

western Maine coastal current. Deep-Sea Res. II 52: 2392-2410.

544 Cobb, J.S., Wang, D., Campbell, D.B., and Rooney, P. 1989. Speed and direction of swimming 545 by postlarvae of the American lobster. Trans. Am. Fish. Soc. 118: 82-86.

547 Cowen, R.K., Paris, C.B., and Srinivasan, A. 2006. Scaling of connectivity in marine $548 \quad$ populations. Science, 311: 522-527.

549 Ennis, G. P. and Fogarty, M. J. (1997). Recruitment overfishing reference point for the 550 American lobster (Homarus americanus). Mar. Freshwater. Res.48: 1029-1034.

551 Fogarty, M.J., and Idoine, J.S. 1986. Recruitment dynamics in an American lobster (Homarus 552 americanus) population. Can. J. Fish. Aquat. Sci. 43: 2368-2376.

553 Gelman, A. 2006. Prior distributions for variance parameters in hierarchical models. Bayesian $554 \quad$ Anal. 1: 515-534.

555 Gelman, A., Meng, X., and Stern, H. 1996. Posterior predictive assessment of model fitness via 556 realized discrepancies (with discussion). Stat. Sin. 6: 733-807.

557 Gelman, A., Carlin, J.B., Stern, H.S. and Rubin, D.B. 2004. Bayesian Data Analysis. Chapman 558 and Hall, London.

559 Henderson-Sellers, A., Wilson, M. F., and Thomas, G. 1985. The effect of spatial resolution on $560 \quad$ archives of land cover type. Clim. Change, 7(4), 391-402.

561 Hilborn, R., and Walters, C.J. 1992. Quantitative fisheries stock assessment: choice, dynamics 
and uncertainty. Chapman and Hall, New York.

563 Incze, L.S., Richard, A.W., and Stanley, C.J. 1997. Quantitative relationships between

564 postlarval production and benthic recruitment in lobsters. Mar. Freshwater. Res. 48(8):

$565 \quad 729-743$.

566 Incze, L., Xue, H., Wolff, N., Xu, D., Wilson, C., Steneck, R., Wahle, R., Lawton, P., Pettigrew,

567 N., and Chen, Y. 2010. Connectivity of lobster populations in the coastal Gulf of Maine.

568 Part II. Coupled biophysical dynamics. Fish. Oceanogr. 19(1): 1-20.

569 Josefson, A.B. 2009. Additive partitioning of estuarine benthic macroinvertebrate diversity

570 across multiple spatial scales. Mar. Ecol. Prog. Ser. 396:283-292.

571 Lawton P., and Lavalli K.L. 1995. Postlarval, juvenile, adolescent and adult ecology. In: Factor

572 JR (Ed) Biology of the lobster: Homarus americanus. Academic Press, San Diego, CA.

573 Levin S.A. 1992. The problem of pattern and scale in ecology. Ecology, 73:1943-1967

574 Lunn, J.D., Thomas, A., Best, N., and Spiegelhalter, D. 2000. Win-BUGS — a Bayesian

575 modelling framework: concepts, structure, and extensibility. Stat. Comput. 10: 325-337.

576 Lynch, D.R., Holbrook, M.J., Naimie, C.E., 1997. The Maine coastal current: spring

577 climatological circulation. Continental Shelf Research 17, 605-634.

578 Manning, J.P., McGillicuddy Jr, D.J., Pettigrew, N.R., Churchill, J.H., and Incze, L.S. 2009.

579 Drifter observations of the Gulf of Maine coastal current. Cont. Shelf. Res. 29(7):

580 $835-845$. 
581 Meentemeyer, V., and Box, E.O. 1987. Scale effects in landscape studies. Landscape

582 heterogeneity and disturbance. Springer New York.

583 McManus, M.C., Oviatt, C.A., Giblin, A.E., Tucker, J., and Turner, J.T. 2014. The Western

584 Maine Coastal Current reduces primary production rates, zooplankton abundance and

585 benthic nutrient fluxes in Massachusetts Bay. ICES J. Mar. Sci. 71(5):1158-1169.

586 Meng, X. 1994. Posterior predictive p-values. Ann. Stat. 22: 1142-1160.

587 Mercaldo-Allen, R. and Kuropat C.A. 1994. The American lobster, Homarus americanus,:

588 habitat requirements and responses to contaminant exposures. NMFS-NE-105.

589 Michielsens, C.G.J., and McAllister, M.K. 2004. A Bayesian hierarchical analysis of

590 stock-recruit data: quantifying structural and parameter uncertainties. Can. J. Fish. Aquat.

$591 \quad$ Sci. 61(6): 1032-1047.

592 Millar, R.B. 2002. Reference priors for Bayesian fisheries models. Can. J. Fish. Aquat.

593 Sci. 59(9): 1492-1502.

594 Myers, R.A., Hutchings, J.A., and Barrowman, N.J. 1996. Hypothesis for the decline of cod

595 in the North Atlantic. Mar. Ecol. Prog. Ser. 138: 293-308.

596 Myers, R.A., Mertz, G., and Bridson, J. 1997. Spatial scales of interannual recruitment

597 variations of marine, anadromous, and freshwater fish. Can. J. Fish. Aquat. Sci. 54(6):

$598 \quad 1400-1407$.

599 Needle C.L. 2001. Recruitment models: diagnosis and prognosis. Rev. Fish. Biol. Fisher. 11: 
600 95-111.

601 Oppenheim, N.G., and Wahle, R.A. 2013. Cannibals by night? In situ video monitoring reveals 602 diel shifts in inter-and intra-specific predation on the American lobster 1. Can. J. Fish. $603 \quad$ Aquat. Sci. 70(11): 1635-1640.

604 Pettigrew, N.R., Townsend, D.W., Xue, H., Wallinga, J.P., Brickley, P.J., and Hetland, R.D. 605 1998. Observations of the Eastern Maine Coastal Current and its offshore extensions in 606 1994. J. Geo. Res. 103(C13): 30623-30639.

607 Pettigrew, N.R., Churchill, J.H., Janzen, C.D., Mangum, L.J., Signell, R.P., Thomas, A.C., 608 Townsend, D.W., Wallinga, J.P., and Xue, H.J. 2005. The kinematic and hydrographic 609 structure of the Gulf of Maine Coastal Current. Deep-Sea Res. Part II Top. Stud.

$610 \quad$ Oceanogr. 52(19-21): 2369-2391.

611 Pineda, J., Reyns, N.B., and Starczak, V.R. 2009. Complexity and simplification in 612 understanding recruitment in benthic populations. Popul. Ecol., 51(1), 17-32.

613 Punt, A., and Hilborn, R. 1997. Fisheries stock assessment and decision analysis: the Bayesian 614 approach. Rev. Fish Biol. Fish. 7: 35-65.

615 Quinn, T.J., and Deriso, R.B. 1999. Quantitative fish dynamics. Oxford University Press, New $616 \quad$ York.

617 R Development Core Team. 2013. R: a language and environment for statistical computing.

618 Rahbek, C. 2005. The role of spatial scale and the perception of large-scale species-richness 
patterns. Ecol. Lett. 8(2): 224-239.

620 Ricker, W.E. 1954. Stock and recruitment. J. Fish. Res. Board. Can. 11:559-623.

621 Robert, C.P., Chopin, N., and Rousseau, J. 2009. Harold Jeffreys's Theory of Probability

622 revisited. Stat. Sci., 141-172.

623 Schneider D.C. 2001. The rise of the concept of scale in ecology. Bioscience, 51:545-553.

624 Steneck, R.S. 2006. Staying connected in a turbulent world. Science,,311(5760): 480-481.

625 Turner, M.G., O’Neill, R.V., Gardner, R.H., and Milne, B.T. 1989. Effects of changing spatial

626 scale on the analysis of landscape pattern. Landscape. Ecol. 3: 153-162.

627 Townsend, D.W. 1991. Influences of oceanographic processes on the biological productivity

628 of the Gulf of Maine. Rev. Aquat. Sci. 5: 211-230.

629 Wahle, R.A., and Incze, L.S. 1997. Pre- and post-settlement processes in recruitment of the 630 American lobster. J. Exp. Mar. Biol. Ecol. 217(2): 179-207.

631 Wahle, R., Incze, L., and Fogarty, M.J. 2004. First projections of American lobster fishery

632 recruitment using a settlement index and variable growth. Bull. Mar. Sci. 74: 101-114.

633 Wahle, R.A., Bergeron, C., Tremblay, J., Wilson, C., Burdett-Coutts, V., Comeau, M., Rochette,

634 R., Lawton, P., Glenn, R., and Gibson, M. 2013a. The geography and bathymetry of

635 American lobster benthic recruitment as measured by diver-based suction sampling and

636 passive collectors. Mar. Biol. Res. 9(1): 42-58.

637 Witman, J.D., Etter, R.J., and Smith, F. 2004. The relationship between regional and local 
638 species diversity in marine benthic communities: a global perspective. Proc. Nat. Acad.

639 Sci. U.S.A. 101(44): 15664-15669.

640 Xue, H., Incze, L., Xu, D., Wolff N., and Pettigrew N. 2008. Connectivity of lobster

641 populations in the coastal Gulf of Maine. Part I: Circulation and larval transport

642 potential. Ecol. Model. 210: 193-211. 
643 Table 1 Summary of posterior distributions for the stock-recruitment model parameters by 644 model type, spatial scale, and region.

\begin{tabular}{|c|c|c|c|c|c|c|c|c|}
\hline \multirow[b]{2}{*}{ Model } & \multirow[b]{2}{*}{ Region } & \multirow[b]{2}{*}{ Scale $(\mathrm{km})$} & \multicolumn{3}{|c|}{$\alpha$} & \multicolumn{3}{|c|}{$\beta$} \\
\hline & & & $\hat{R}_{f}$ & Mean & $95 \% \mathrm{CI}$ & $\hat{R}_{f}$ & Mean & $95 \% \mathrm{CI}$ \\
\hline B-H & East & 0.125 & 1.002 & 17657800 & $(841100,67190000)$ & 1.002 & 11168550 & $(377900,42680000)$ \\
\hline B-H & East & 0.25 & 1.008 & 4174330 & $(180800,13570000)$ & 1.008 & 2641645 & $(131300,8603000)$ \\
\hline B-H & East & 0.5 & 1.016 & 12895720 & $(430300,57190000)$ & 1.016 & 8199449 & $(167400,35590000)$ \\
\hline B-H & East & 1 & 1.014 & 5663037 & $(207400,19890000)$ & 1.014 & 3584460 & $(136300,12690000)$ \\
\hline B-H & East & 2 & 1.016 & 5258921 & $(188100,19100000)$ & 1.016 & 3325061 & $(114400,11880000)$ \\
\hline B-H & East & 4 & 1.090 & 5859515 & $(78720,27850000)$ & 1.090 & 3740566 & $(51410,17500000)$ \\
\hline B-H & East & 8 & 1.013 & 2292601 & $(232800,6446000)$ & 1.013 & 1427700 & $(140500,4070000)$ \\
\hline B-H & East & 16 & 1.015 & 5272730 & $(181400,19970000)$ & 1.015 & 3353335 & $(121700,12720000)$ \\
\hline B-H & East & 32 & 1.034 & 2336967 & $(78310,7608000)$ & 1.034 & 1480368 & $(28090,4763000)$ \\
\hline B-H & East & 64 & 1.023 & 823661 & $(40390,2808000)$ & 1.024 & 520997 & $(24460,1801000)$ \\
\hline B-H & East & 128 & 1.057 & 588102 & $(27280,1891000)$ & 1.056 & 361240 & $(14640,1160000)$ \\
\hline B-H & West & 0.125 & 1.006 & 5701604 & $(229000,19880000)$ & 1.006 & 2924222 & $(122200,10170000)$ \\
\hline B-H & West & 0.25 & 1.008 & 4626319 & $(260300,16340000)$ & 1.008 & 2369218 & $(155000,8411000)$ \\
\hline B-H & West & 0.5 & 1.018 & 6590609 & $(256600,31090000)$ & 1.019 & 3373607 & $(127200,16160000)$ \\
\hline B-H & West & 1 & 1.005 & 2365896 & $(184200,7535000)$ & 1.005 & 1213146 & $(91100,3872000)$ \\
\hline B-H & West & 2 & 1.012 & 2299235 & $(124100,6103000)$ & 1.012 & 1184195 & $(66360,3129000)$ \\
\hline B-H & West & 4 & 1.008 & 2082435 & $(133900,6534000)$ & 1.008 & 1067173 & $(68350,3295000)$ \\
\hline B-H & West & 8 & 1.058 & 1058384 & $(70870,3481000)$ & 1.058 & 544013 & $(37270,1758000)$ \\
\hline B-H & West & 16 & 1.040 & 1158222 & $(64500,3969000)$ & 1.040 & 601667 & $(32300,2083000)$ \\
\hline B-H & West & 32 & 1.003 & 1005963 & $(61050,3185000)$ & 1.003 & 524957 & $(32900,1656000)$ \\
\hline B-H & West & 64 & 1.009 & 600675 & $(91460,1474000)$ & 1.009 & 312582 & $(37870,769500)$ \\
\hline B-H & West & 128 & 1.051 & 824013 & $(85090,1668000)$ & 1.051 & 440276 & $(43130,893200)$ \\
\hline Ricker & East & 0.125 & 1.001 & 109.40 & $(63.62,161.7)$ & 1.001 & 6.14 & $(4.276,7.862)$ \\
\hline Ricker & East & 0.25 & 1.002 & 63.05 & $(42.7,86.2)$ & 1.002 & 5.22 & $(3.853,6.541)$ \\
\hline Ricker & East & 0.5 & 1.001 & 54.72 & $(37.27,76.48)$ & 1.001 & 4.96 & $(3.519,6.222)$ \\
\hline Ricker & East & 1 & 1.001 & 49.30 & $(33.29,67.01)$ & 1.002 & 4.65 & $(3.559,5.846)$ \\
\hline Ricker & East & 2 & 1.001 & 49.93 & $(31.07,70.26)$ & 1.001 & 5.06 & $(3.804,6.308)$ \\
\hline Ricker & East & 4 & 1.001 & 79.42 & $(46.47,115.3)$ & 1.001 & 6.20 & $(4.629,7.737)$ \\
\hline Ricker & East & 8 & 1.006 & 57.60 & $(33.43,82.01)$ & 1.010 & 5.52 & $(3.694,7.079)$ \\
\hline Ricker & East & 16 & 1.001 & 52.74 & $(31.34,78.06)$ & 1.001 & 5.67 & $(4.003,7.203)$ \\
\hline Ricker & East & 32 & 1.004 & 85.88 & $(24.66,155.1)$ & 1.003 & 6.18 & $(4.348,8.023)$ \\
\hline Ricker & East & 64 & 1.005 & 130.96 & $(3.829,356.2)$ & 1.013 & 5.62 & $(2.53,8.434)$ \\
\hline Ricker & East & 128 & 1.004 & 127.61 & $(4.735,350.7)$ & 1.003 & 5.63 & $(2.422,8.447)$ \\
\hline Ricker & West & 0.125 & 1.001 & 66.57 & $(52.88,79.38)$ & 1.002 & 4.73 & $(3.676,5.748)$ \\
\hline Ricker & West & 0.25 & 1.001 & 68.63 & $(56.35,81.39)$ & 1.001 & 4.72 & $(3.717,5.747)$ \\
\hline Ricker & West & 0.5 & 1.002 & 57.09 & $(46.07,67.89)$ & 1.001 & 4.76 & $(3.748,5.744)$ \\
\hline Ricker & West & 1 & 1.001 & 42.44 & $(34.2,51.44)$ & 1.001 & 4.15 & $(3.286,5.061)$ \\
\hline Ricker & West & 2 & 1.002 & 33.61 & $(26.6,41.08)$ & 1.002 & 3.99 & $(3.169,4.869)$ \\
\hline Ricker & West & 4 & 1.001 & 35.47 & $(25.74,44.95)$ & 1.001 & 4.42 & $(3.289,5.44)$ \\
\hline Ricker & West & 8 & 1.002 & 36.12 & $(24.21,51.3)$ & 1.002 & 4.77 & $(3.573,5.996)$ \\
\hline Ricker & West & 16 & 1.001 & 45.86 & $(22.63,72.39)$ & 1.001 & 5.49 & $(3.867,7.308)$ \\
\hline Ricker & West & 32 & 1.001 & 43.49 & $(14.86,82.35)$ & 1.001 & 4.72 & $(2.474,6.792)$ \\
\hline Ricker & West & 64 & 1.005 & 39.76 & $(7.761,88.56)$ & 1.007 & 3.80 & $(1.434,5.9)$ \\
\hline Ricker & West & 128 & 1.008 & 100.11 & $(4.455,278.7)$ & 1.021 & 5.44 & $(1.791,8.989)$ \\
\hline
\end{tabular}


646 Table 2 Overlap coefficients (OV) and Bayesian p-values (p) for all, low-level $(<25$ th

647 percentile), and high-level ( $>75$ th percentile) recruitments by model type, spatial scale, and 648 region.

649

\begin{tabular}{|c|c|c|c|c|c|c|c|c|c|c|c|c|c|}
\hline \multirow{3}{*}{ Region } & \multirow{3}{*}{ Scale } & \multicolumn{6}{|c|}{ B-H Model } & \multicolumn{6}{|c|}{ Ricker Model } \\
\hline & & \multicolumn{2}{|c|}{ All R } & \multicolumn{2}{|c|}{ Low R } & \multicolumn{2}{|c|}{ High R } & \multicolumn{2}{|c|}{ All R } & \multicolumn{2}{|c|}{ Low R } & \multicolumn{2}{|c|}{ High R } \\
\hline & & $\mathrm{OV}$ & $\mathrm{p}$ & OV & $\mathrm{p}$ & $\mathrm{OV}$ & $\mathrm{p}$ & $\mathrm{OV}$ & $\mathrm{p}$ & $\mathrm{OV}$ & $\mathrm{p}$ & $\mathrm{OV}$ & $\mathrm{p}$ \\
\hline East & 0.125 & 0.95 & 0.51 & 0.76 & 0.33 & 0.11 & 0.01 & 0.96 & 0.51 & 0.30 & 0.91 & 0.23 & 0.05 \\
\hline East & 0.25 & 0.93 & 0.54 & 0.72 & 0.31 & 0.12 & 0.01 & 0.95 & 0.53 & 0.02 & 0.00 & 0.04 & 1.00 \\
\hline East & 0.5 & 0.94 & 0.53 & 0.81 & 0.39 & 0.10 & 0.01 & 0.98 & 0.51 & 0.10 & 0.99 & 0.04 & 0.00 \\
\hline East & 1 & 0.93 & 0.53 & 0.78 & 0.33 & 0.13 & 0.01 & 0.95 & 0.52 & 0.20 & 0.96 & 0.01 & 1.00 \\
\hline East & 2 & 0.94 & 0.52 & 0.78 & 0.36 & 0.11 & 0.01 & 0.96 & 0.52 & 0.21 & 0.96 & 0.73 & 0.61 \\
\hline East & 4 & 0.93 & 0.54 & 0.96 & 0.54 & 0.63 & 0.25 & 0.94 & 0.54 & 0.92 & 0.57 & 0.80 & 0.36 \\
\hline East & 8 & 0.97 & 0.50 & 0.96 & 0.47 & 0.93 & 0.46 & 0.96 & 0.53 & 0.97 & 0.48 & 0.94 & 0.52 \\
\hline East & 16 & 0.97 & 0.51 & 0.72 & 0.30 & 0.18 & 0.02 & 0.98 & 0.50 & 0.93 & 0.53 & 0.86 & 0.58 \\
\hline East & 32 & 0.94 & 0.53 & 0.79 & 0.36 & 0.21 & 0.03 & 0.95 & 0.52 & 0.83 & 0.41 & 0.54 & 0.20 \\
\hline East & 64 & 0.96 & 0.51 & 0.76 & 0.33 & 0.20 & 0.03 & 0.94 & 0.53 & 0.85 & 0.40 & 0.37 & 0.11 \\
\hline East & 128 & 0.94 & 0.52 & 0.75 & 0.33 & 0.24 & 0.05 & 0.95 & 0.54 & 0.79 & 0.36 & 0.33 & 0.07 \\
\hline West & 0.125 & 0.91 & 0.45 & 0.25 & 0.05 & 0.06 & 0.01 & 0.05 & 0.01 & 0.00 & 0.00 & 0.10 & 0.99 \\
\hline West & 0.25 & 0.95 & 0.51 & 0.25 & 0.06 & 0.07 & 0.01 & 0.95 & 0.52 & 0.00 & 0.00 & 0.31 & 0.93 \\
\hline West & 0.5 & 0.96 & 0.50 & 0.26 & 0.06 & 0.07 & 0.00 & 0.96 & 0.48 & 0.00 & 0.00 & 0.29 & 0.93 \\
\hline West & 1 & 0.96 & 0.53 & 0.29 & 0.07 & 0.09 & 0.01 & 0.95 & 0.49 & 0.05 & 0.00 & 0.32 & 0.92 \\
\hline West & 2 & 0.96 & 0.50 & 0.29 & 0.06 & 0.08 & 0.01 & 0.95 & 0.53 & 0.13 & 0.02 & 0.55 & 0.79 \\
\hline West & 4 & 0.97 & 0.49 & 0.26 & 0.06 & 0.07 & 0.00 & 0.96 & 0.48 & 0.21 & 0.03 & 0.82 & 0.61 \\
\hline West & 8 & 0.94 & 0.53 & 0.26 & 0.06 & 0.09 & 0.01 & 0.95 & 0.53 & 0.25 & 0.04 & 0.88 & 0.42 \\
\hline West & 16 & 0.96 & 0.53 & 0.25 & 0.05 & 0.12 & 0.02 & 0.94 & 0.52 & 0.17 & 0.03 & 0.71 & 0.31 \\
\hline West & 32 & 0.95 & 0.52 & 0.25 & 0.06 & 0.15 & 0.02 & 0.96 & 0.50 & 0.18 & 0.03 & 0.65 & 0.25 \\
\hline West & 64 & 0.96 & 0.52 & 0.26 & 0.06 & 0.10 & 0.01 & 0.97 & 0.51 & 0.38 & 0.10 & 0.26 & 0.05 \\
\hline West & 128 & 0.94 & 0.53 & 0.28 & 0.06 & 0.13 & 0.02 & 0.95 & 0.50 & 0.29 & 0.07 & 0.21 & 0.04 \\
\hline
\end{tabular}

650

651 


\section{Fig. captions}

653 Fig. 1 Summer schematic diagram of EMCC and WMCC for the upper 40m in the GOM. The 654 letters A-G designate Lobster Management Zones.

655 Fig. 2 Estimated spawning stock size (\# per $\left.792 \mathrm{~m}^{2}\right)$ summarized using smallest $(0.125 \mathrm{~km}, \mathrm{a})$, 656 A-G designate Lobster Management Zones.

Fig. 3 Box plots of square-root-transformed $\alpha$ and $\beta$ parameter estimates of the stock-recruitment models by model type, spatial scale, and region.

Fig. 4 Box plots of deviances of the stock-recruitment models by model type, spatial scale, and region. Black bar $=$ mode.

Fig. 5 Marginal posterior densities for observed (black line) and replicated (gray shade)

Fig. 6 Stock-recruitment relationships with observations (hollowed dots) and marginal western (b) GOM. Black lines are the models of marginal posterior mode and red lines are the models of 500 parameter sets randomly drawn from the marginal posterior 
671 distributions. 
672 Fig. 1

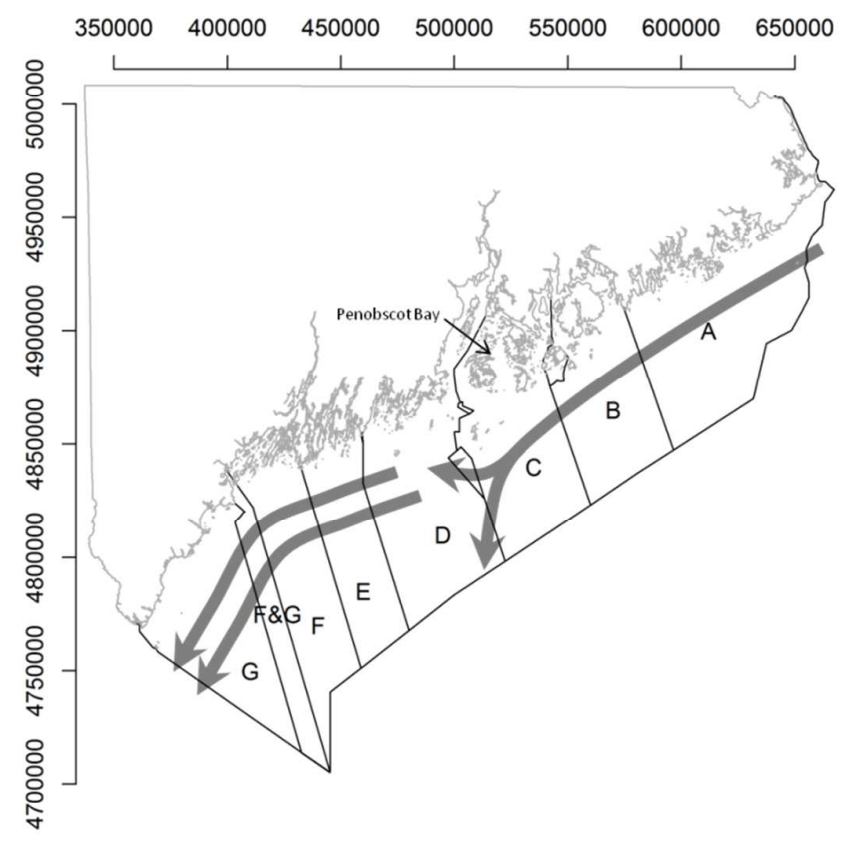

673

674 
675 Fig. 2

$676 \quad$ (a)

677

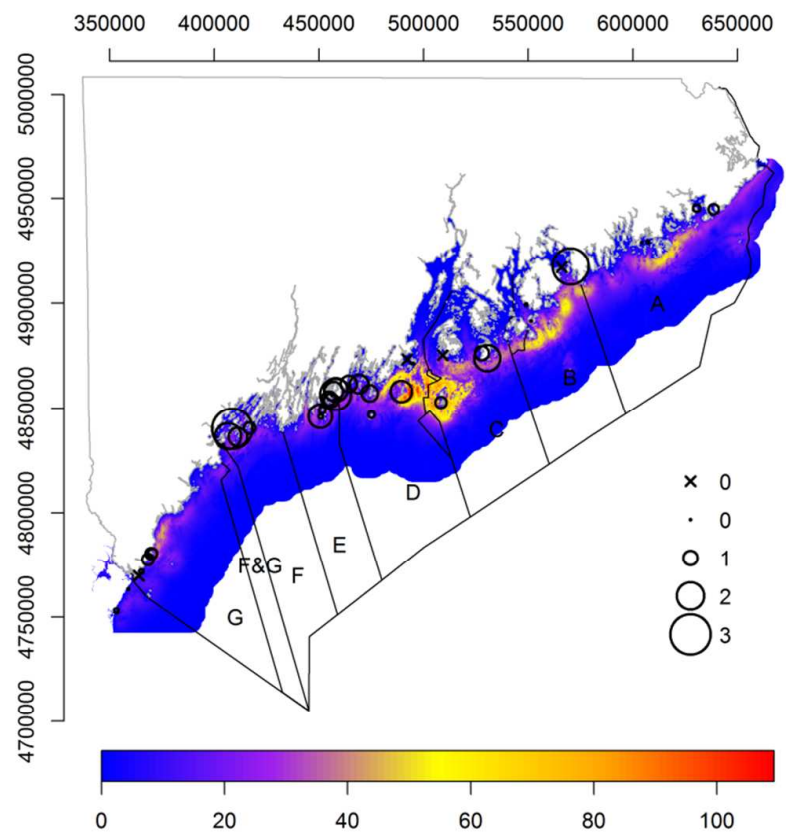

$678 \quad$ (b)

679

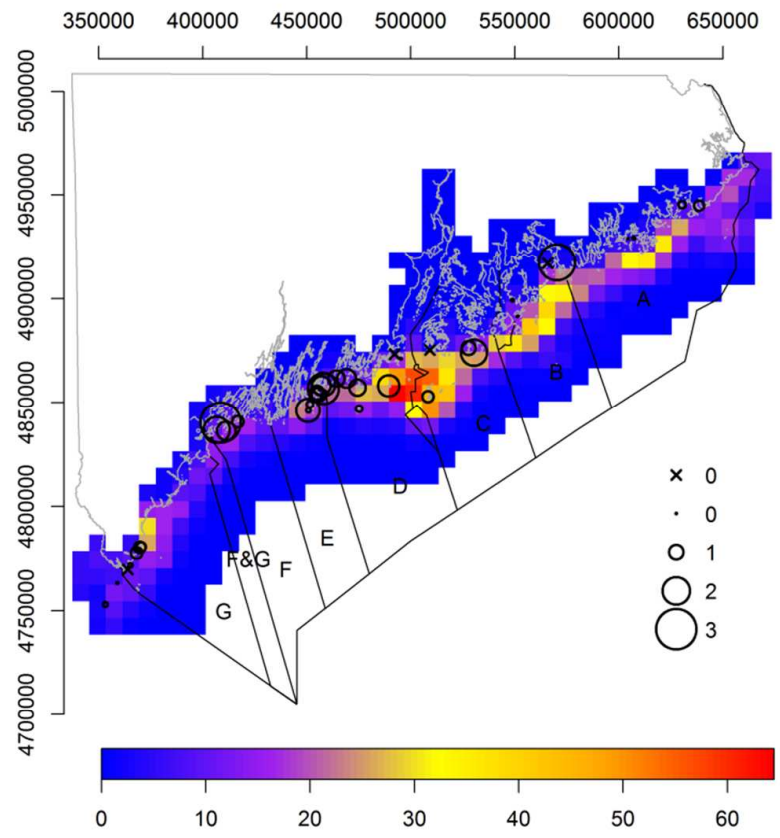

44

https://mc06.manuscriptcentral.com/cjfas-pubs 
$680 \quad(c)$

681

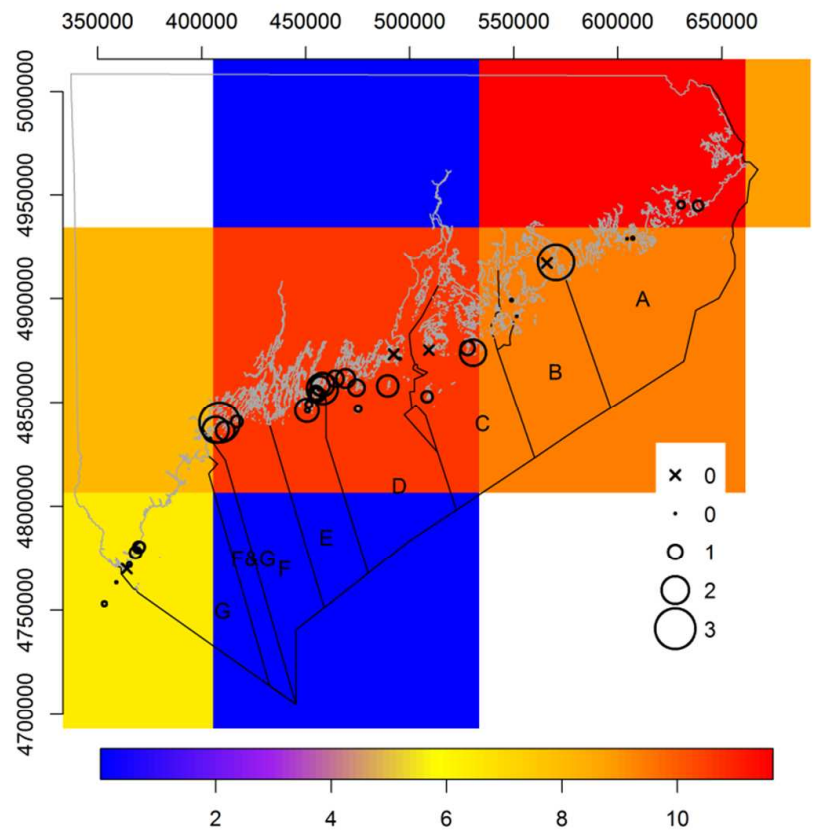


Fig. 3
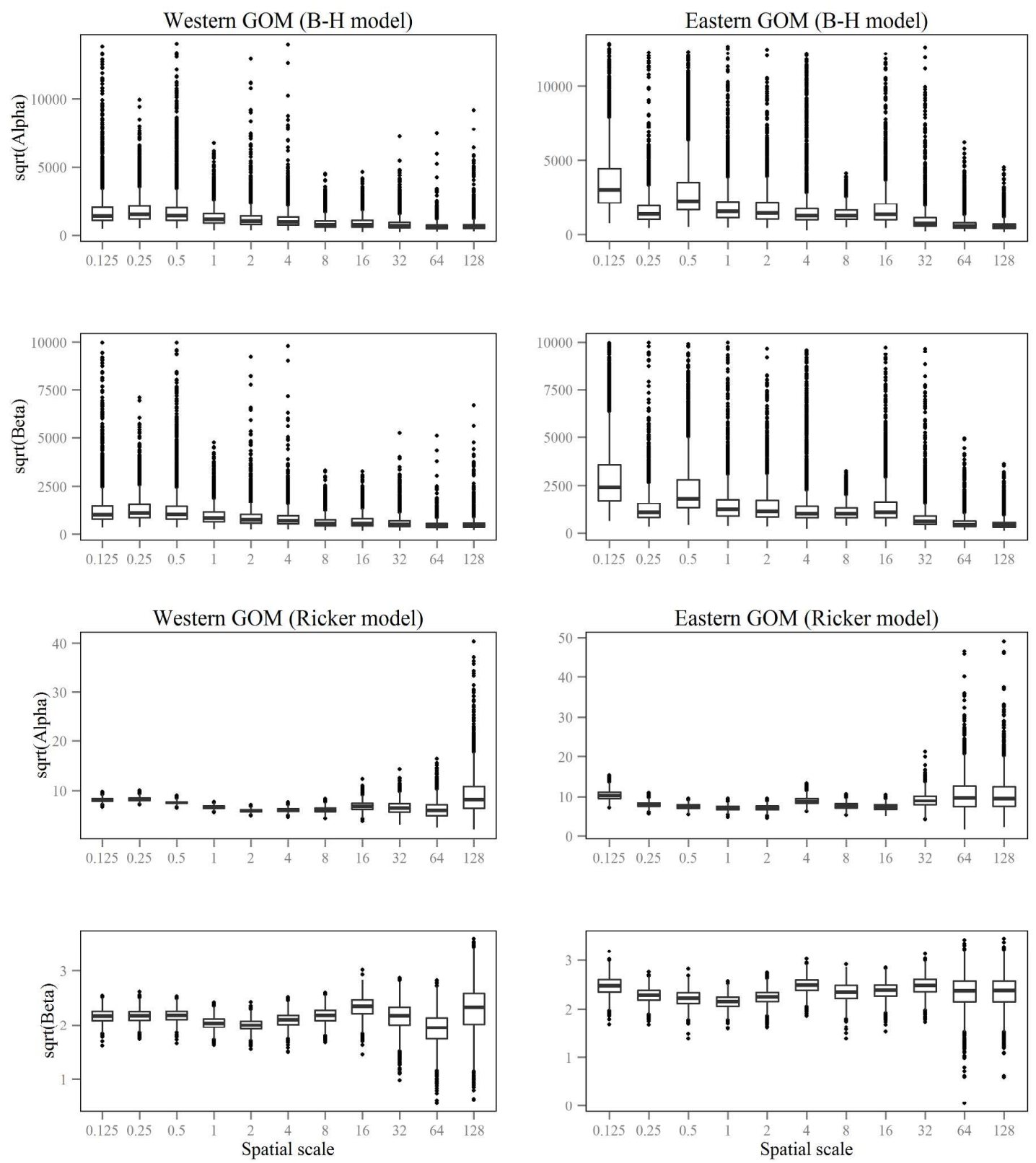

683 
685 Fig. 4

686
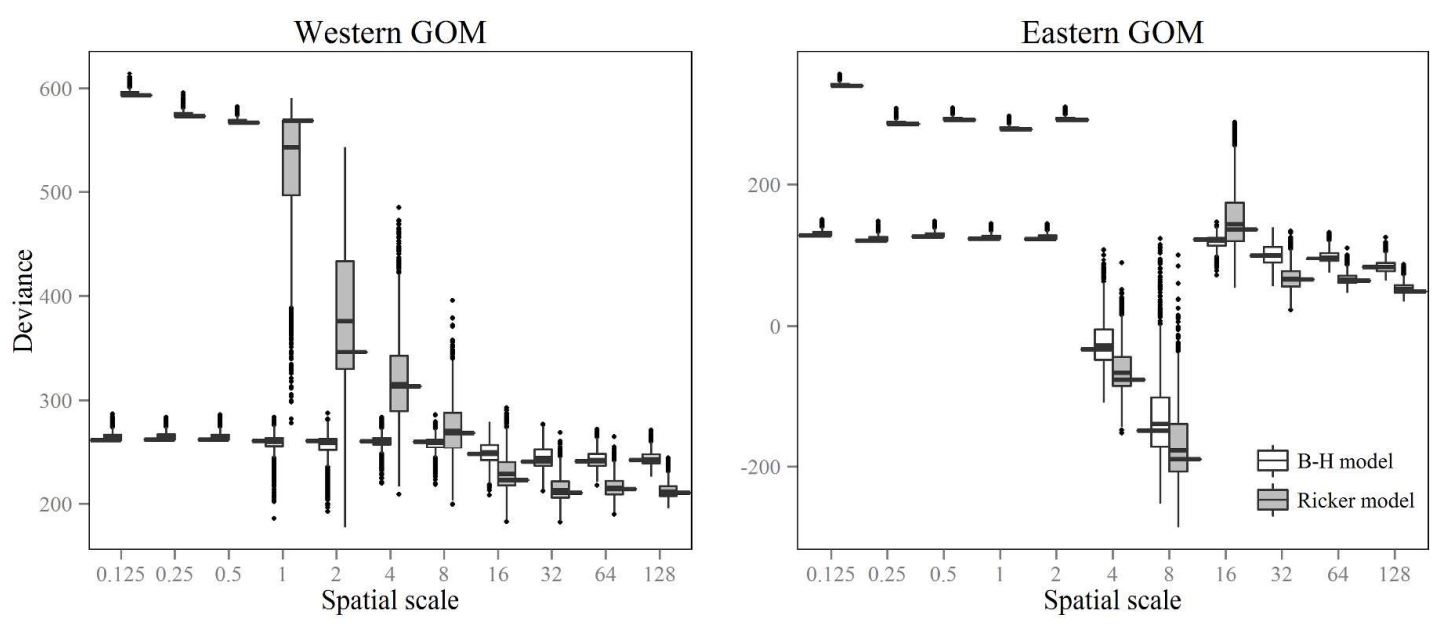

687 
Fig. 5

689

(a)

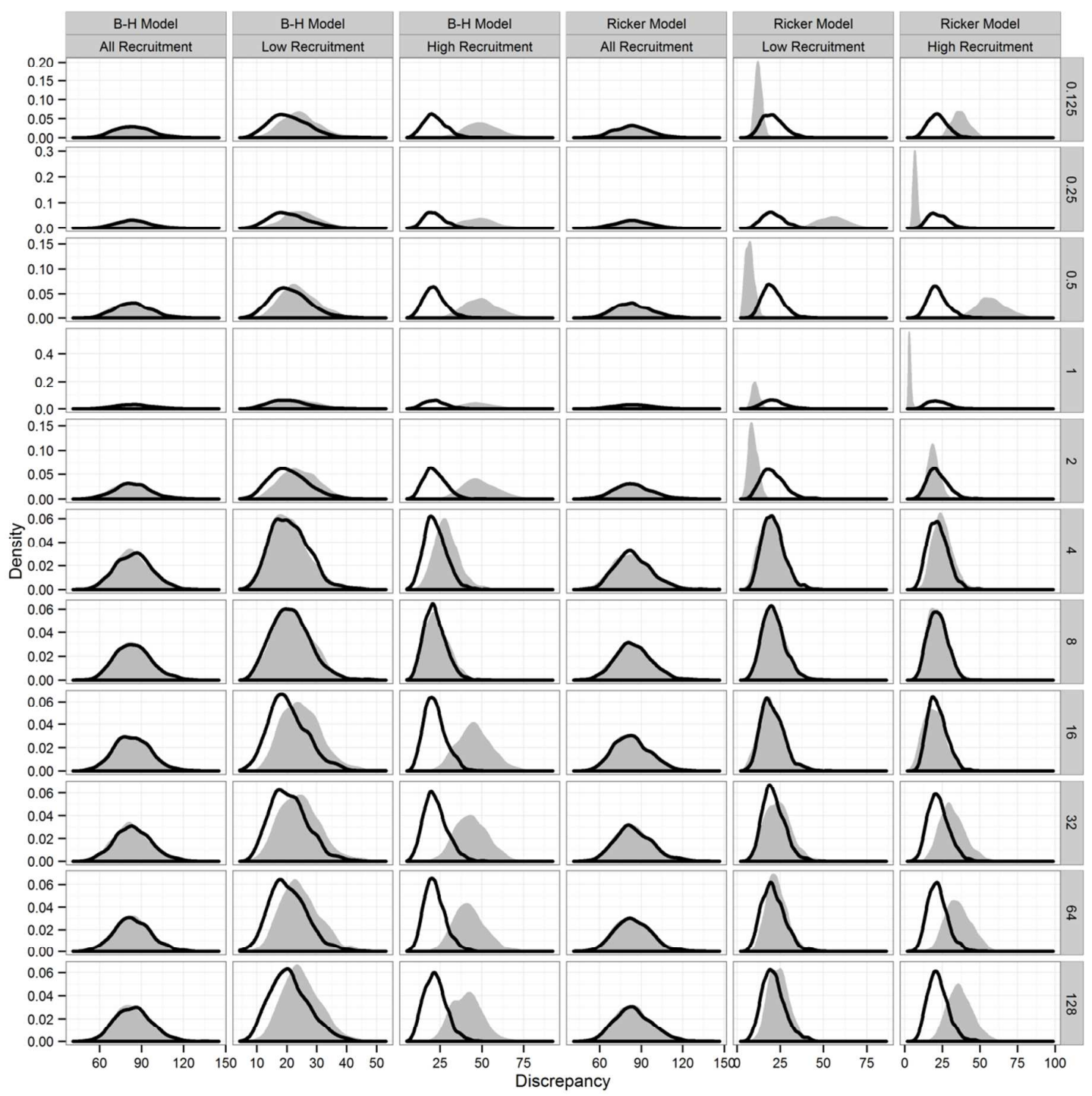




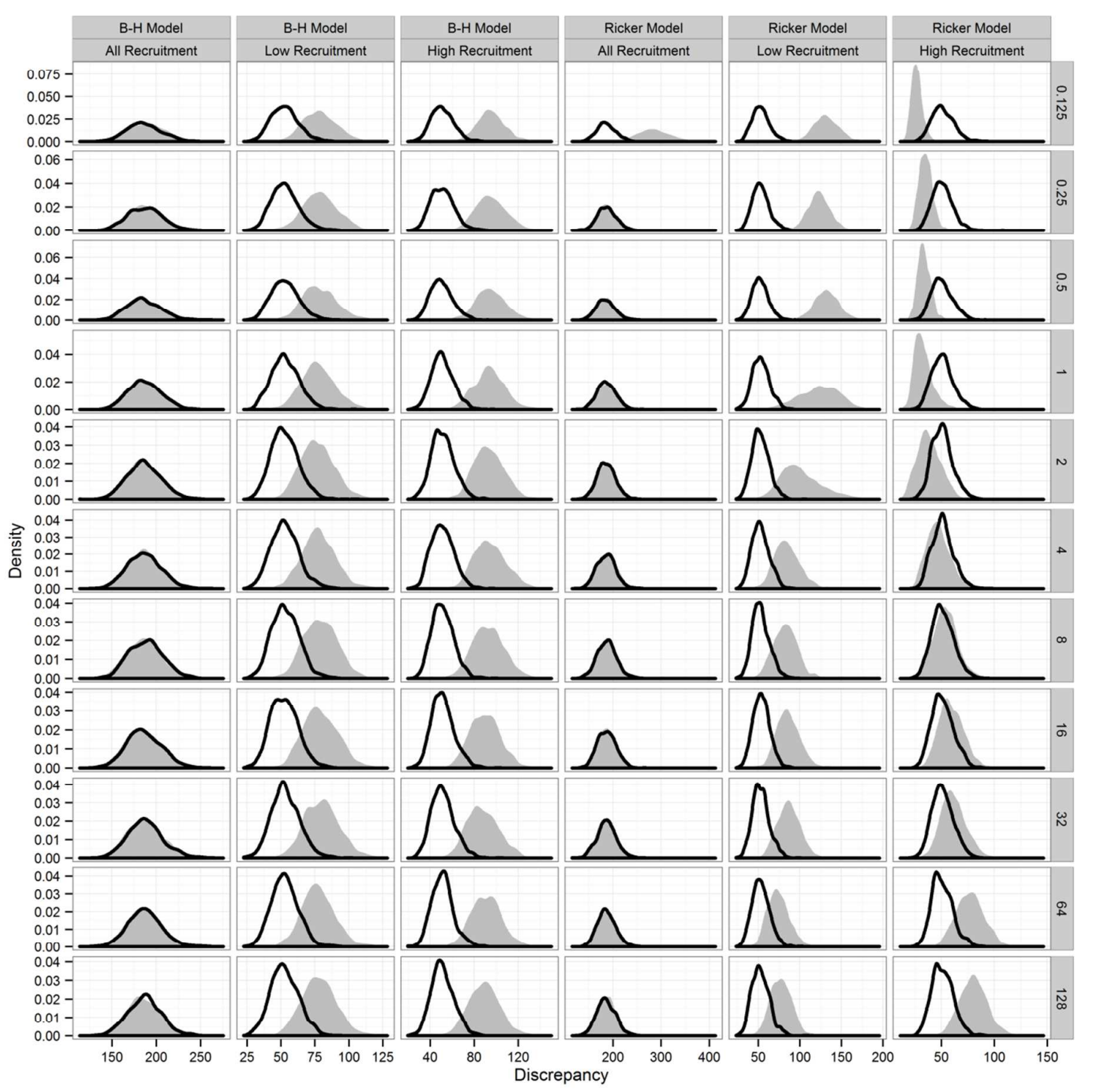


695 Fig. 6

$696 \quad$ (a)

Eastern GOM: B-H model (Spatial scale: $0.125 \mathrm{~km}$ )

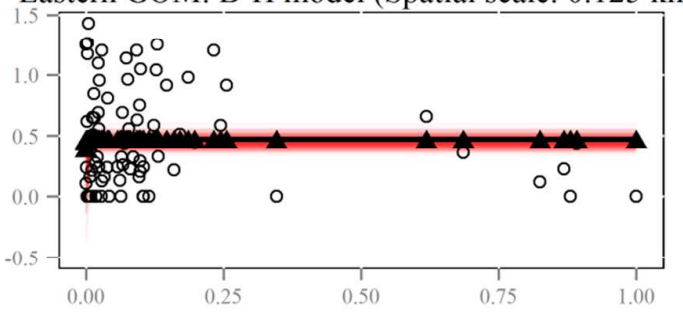

Ricker model (Spatial scale: $0.125 \mathrm{~km}$ )

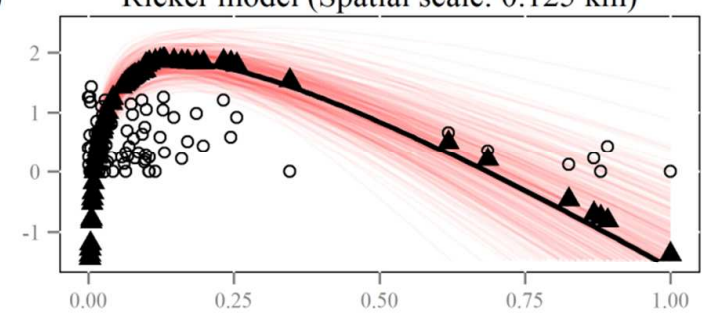

B-H model (Spatial scale: $0.25 \mathrm{~km}$ )
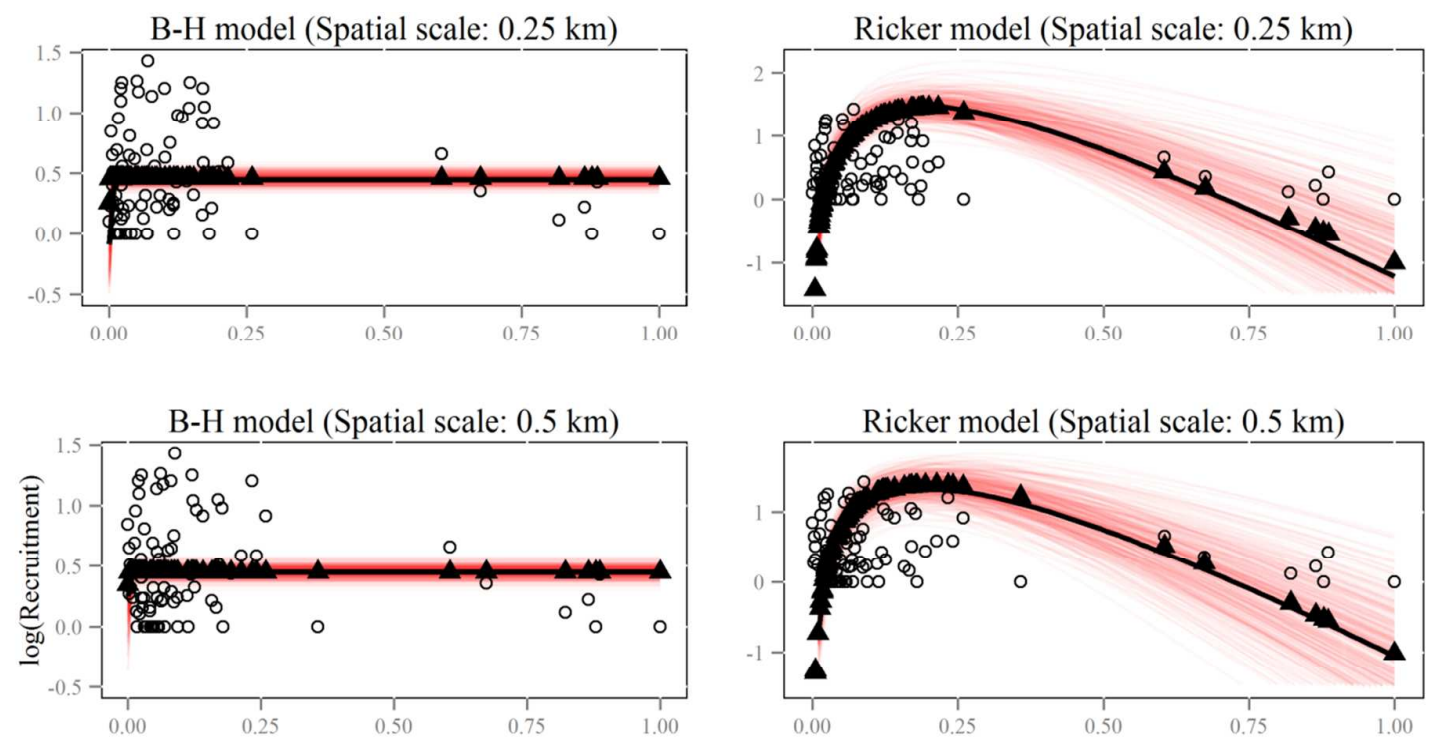

Ricker model (Spatial scale: $0.5 \mathrm{~km}$ )

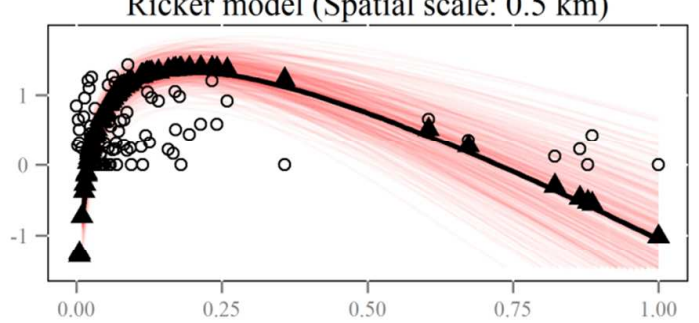

B-H model (Spatial scale: $1 \mathrm{~km}$ )

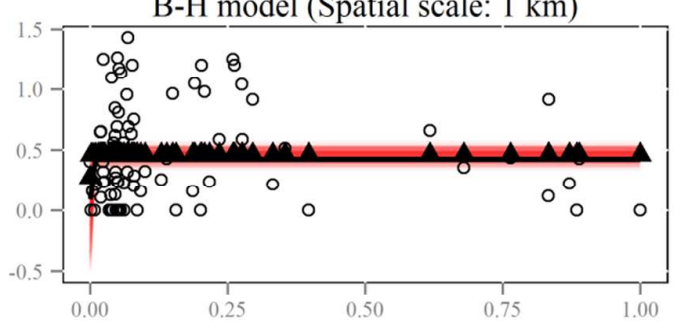

Ricker model (Spatial scale: $1 \mathrm{~km}$ )

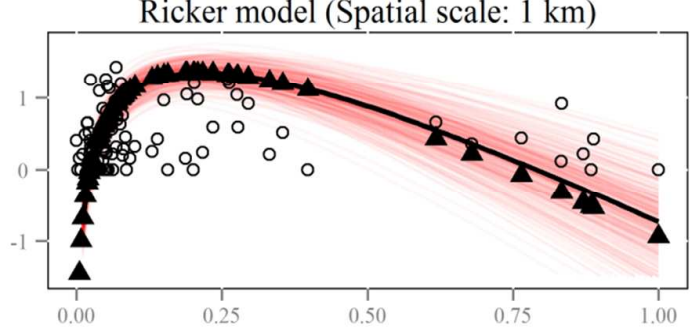

B-H model (Spatial scale: $2 \mathrm{~km}$ )

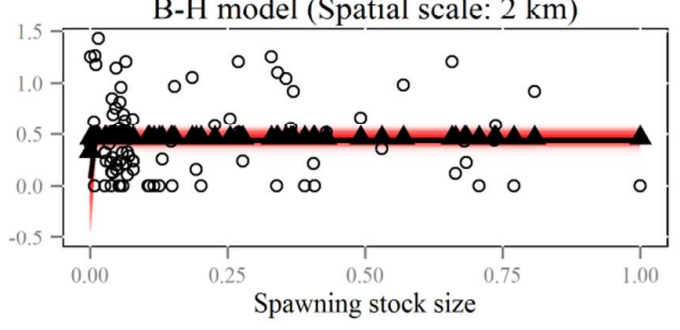

Ricker model (Spatial scale: $2 \mathrm{~km}$ )

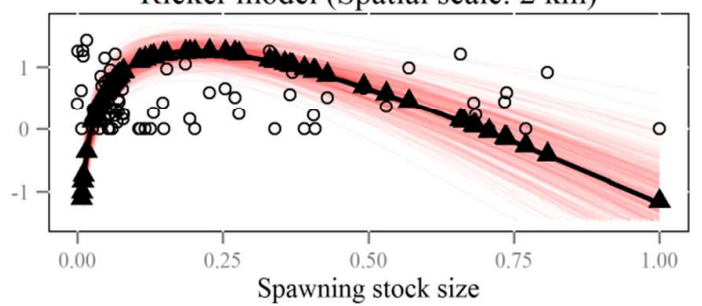

697 

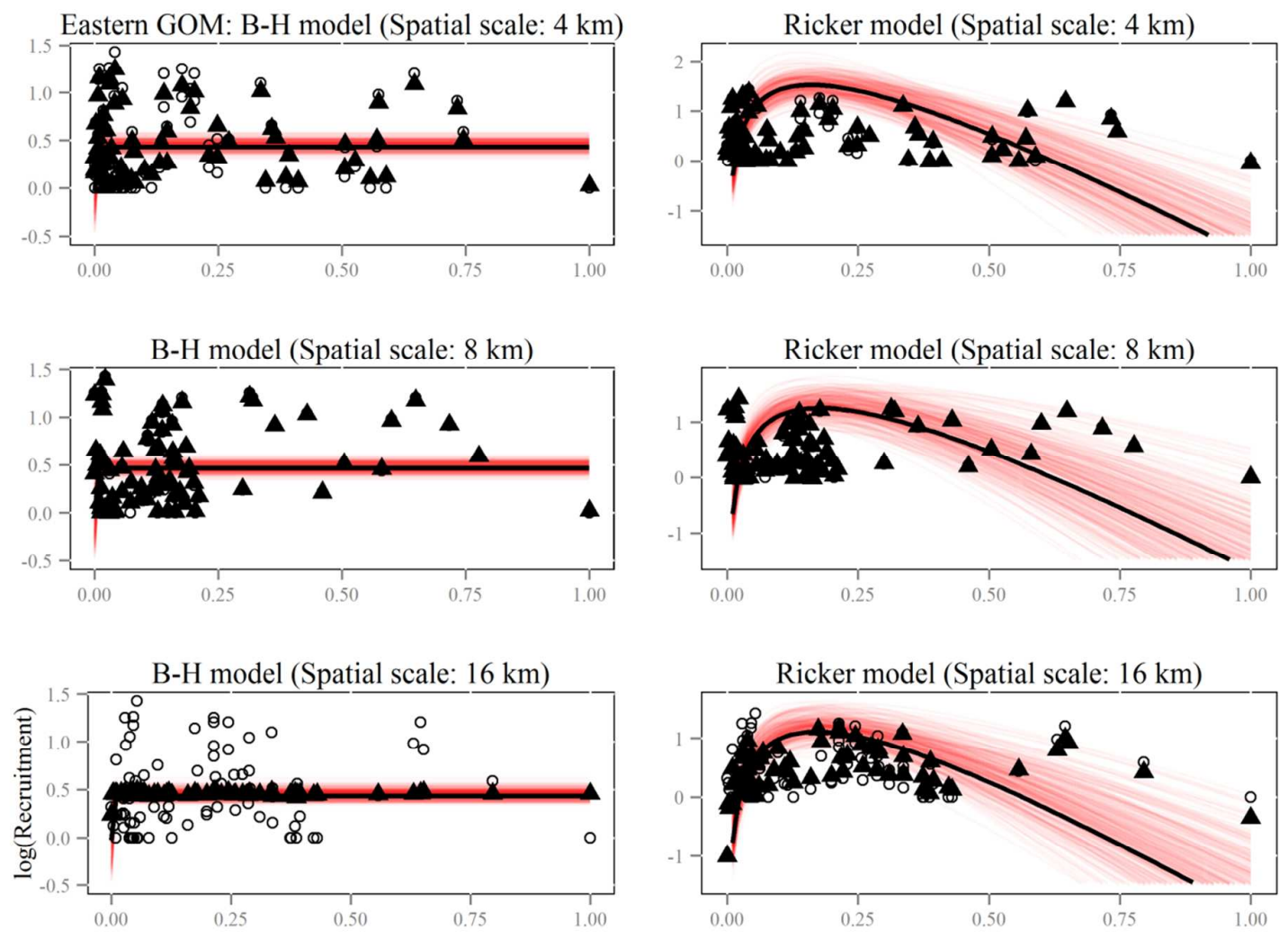

B-H model (Spatial scale: $32 \mathrm{~km}$ )

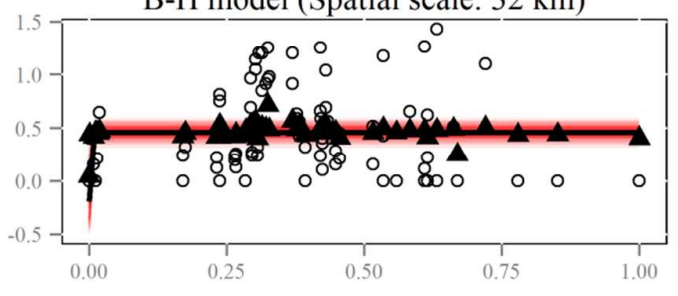

Ricker model (Spatial scale: $32 \mathrm{~km}$ )

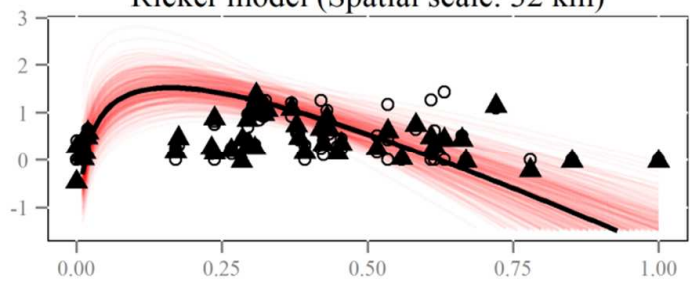

B-H model (Spatial scale: $64 \mathrm{~km}$ )
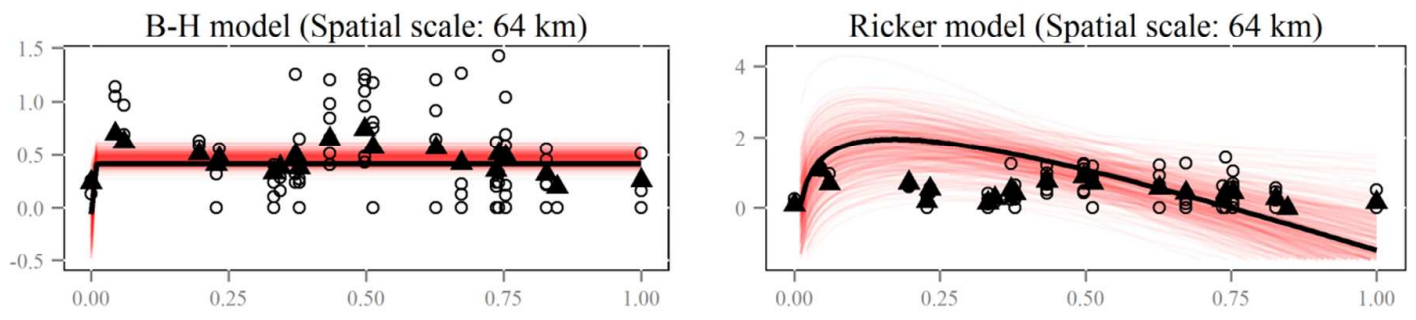

B-H model (Spatial scale: $128 \mathrm{~km}$ )
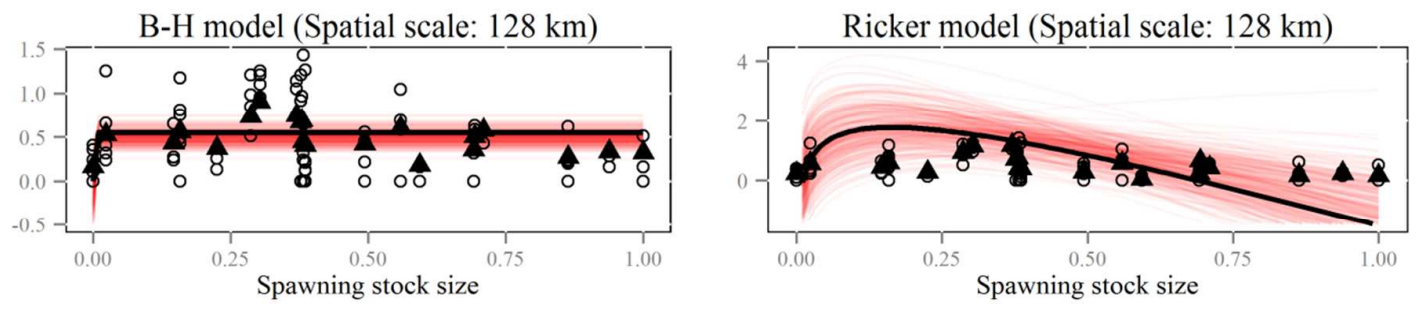

698

699 
Western GOM: B-H model (Spatial scale: $0.125 \mathrm{~km}$
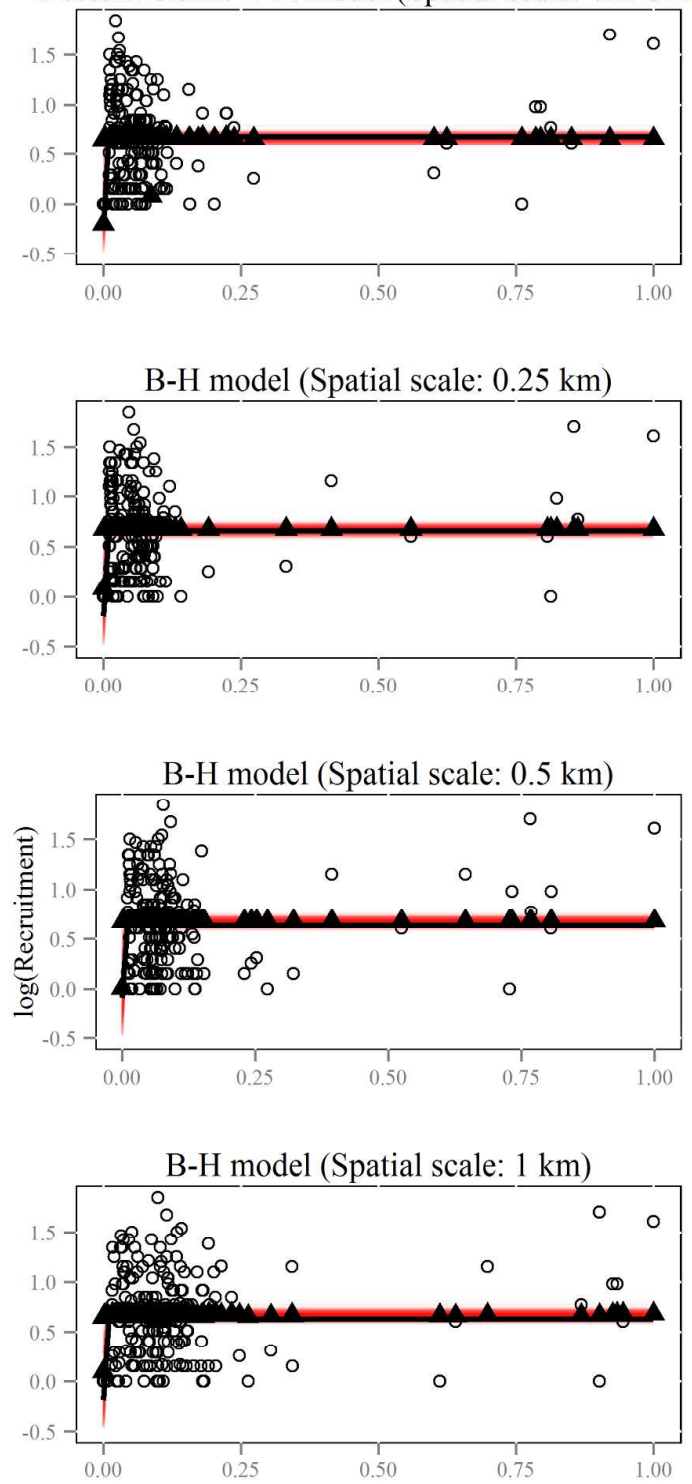

B-H model (Spatial scale: $2 \mathrm{~km}$ )

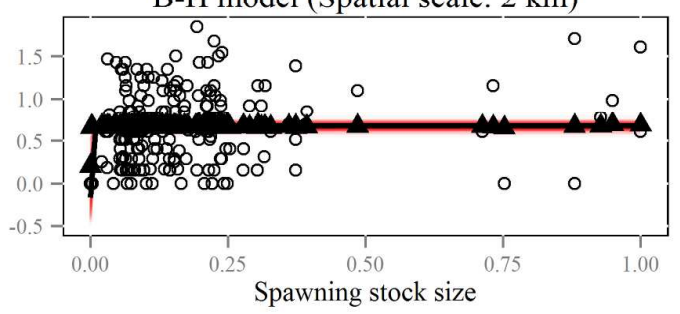

Ricker model (Spatial scale: $0.125 \mathrm{~km}$ )

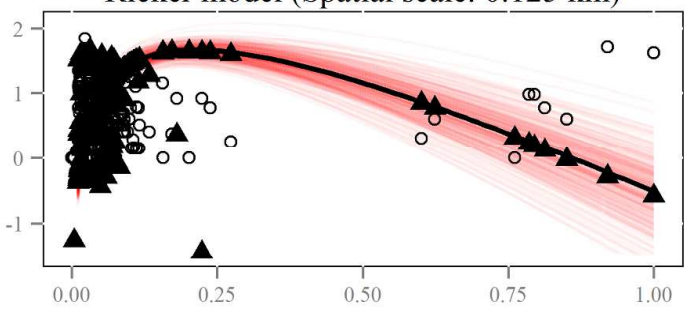

Ricker model (Spatial scale: $0.25 \mathrm{~km}$ )

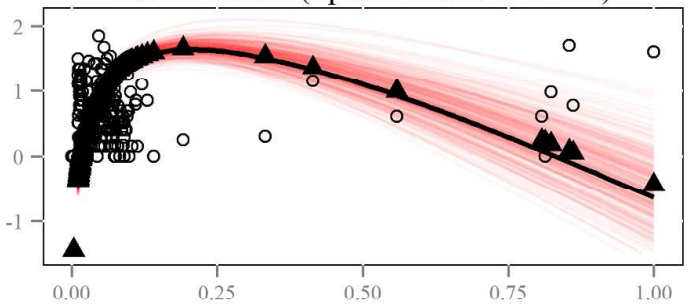

Ricker model (Spatial scale: $0.5 \mathrm{~km}$ )

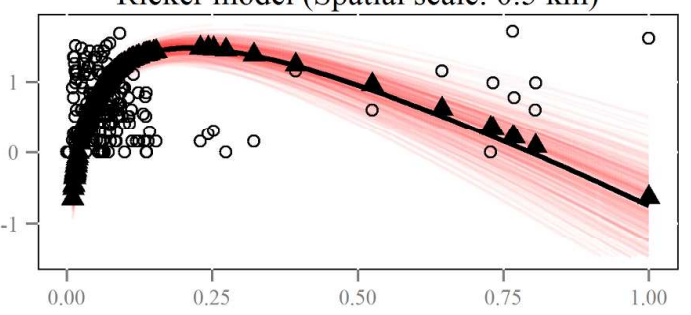

Ricker model (Spatial scale: $1 \mathrm{~km}$ )

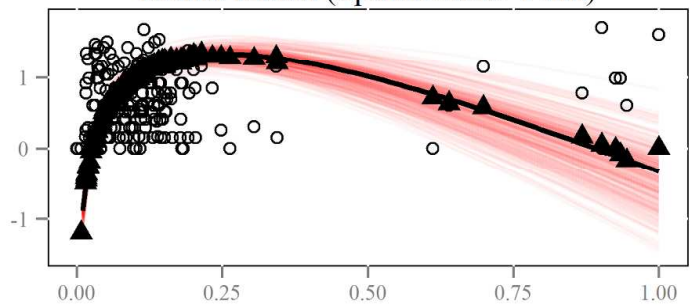

Ricker model (Spatial scale: $2 \mathrm{~km}$ )

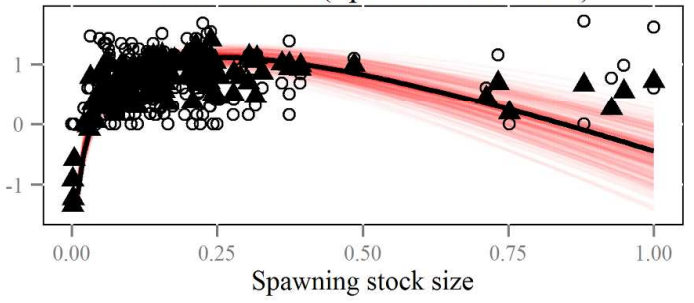

701 

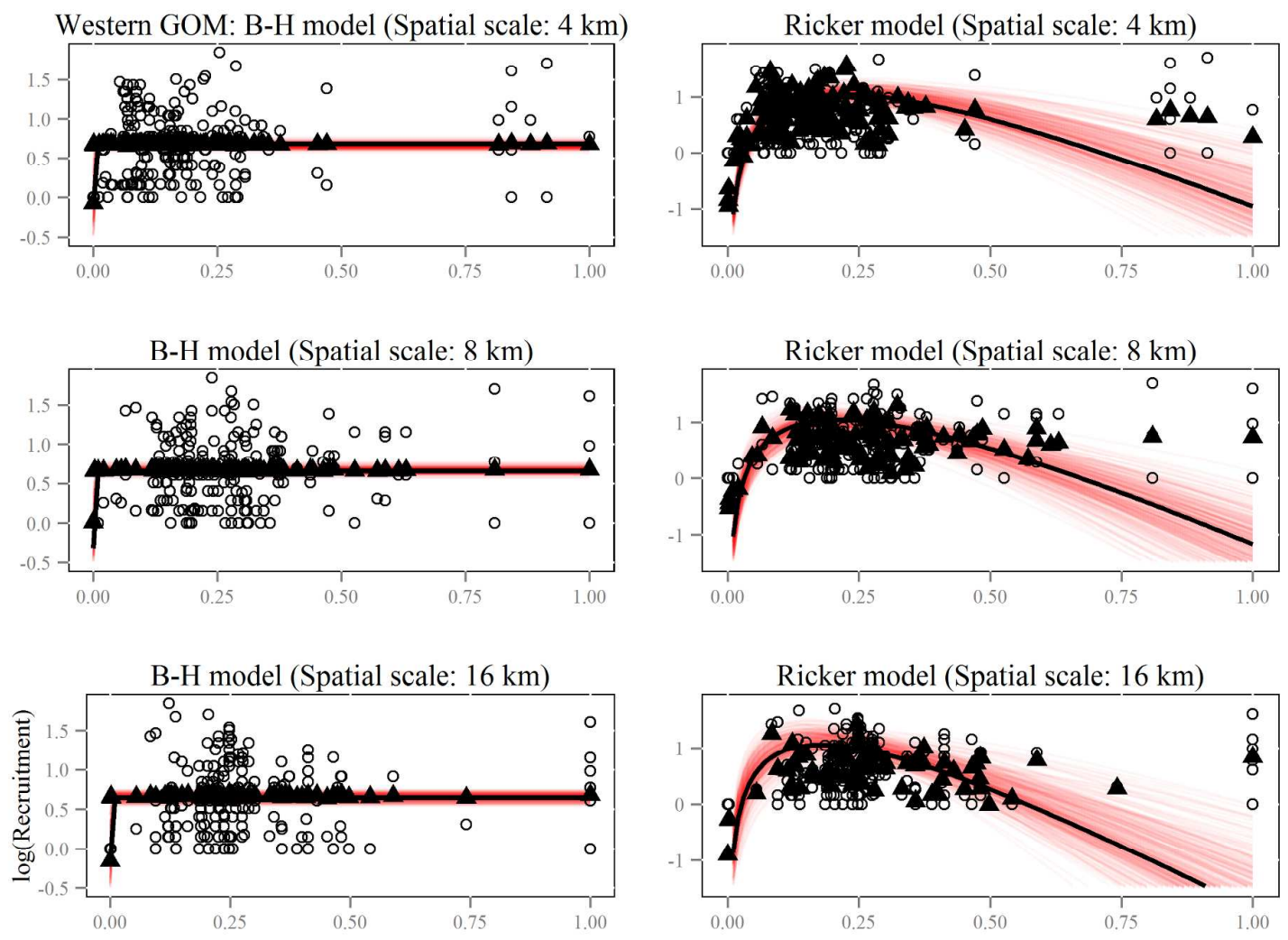

B-H model (Spatial scale: $32 \mathrm{~km})$

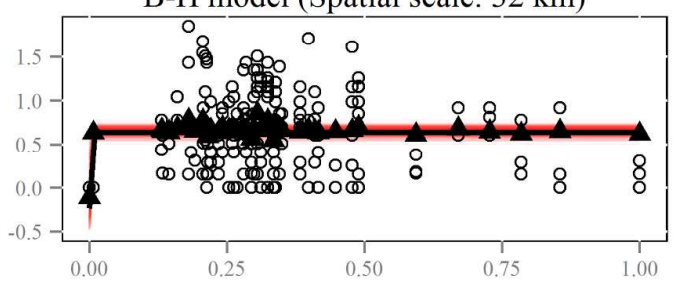

Ricker model (Spatial scale: $32 \mathrm{~km}$ )

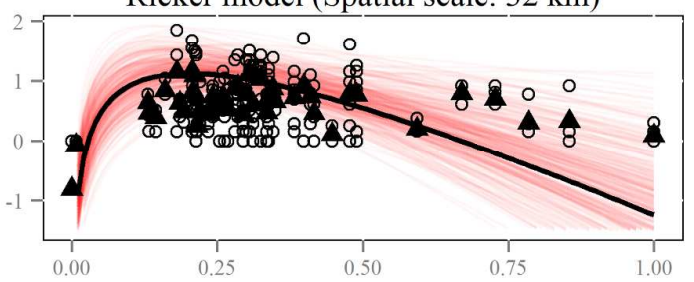

B-H model (Spatial scale: $64 \mathrm{~km}$ )
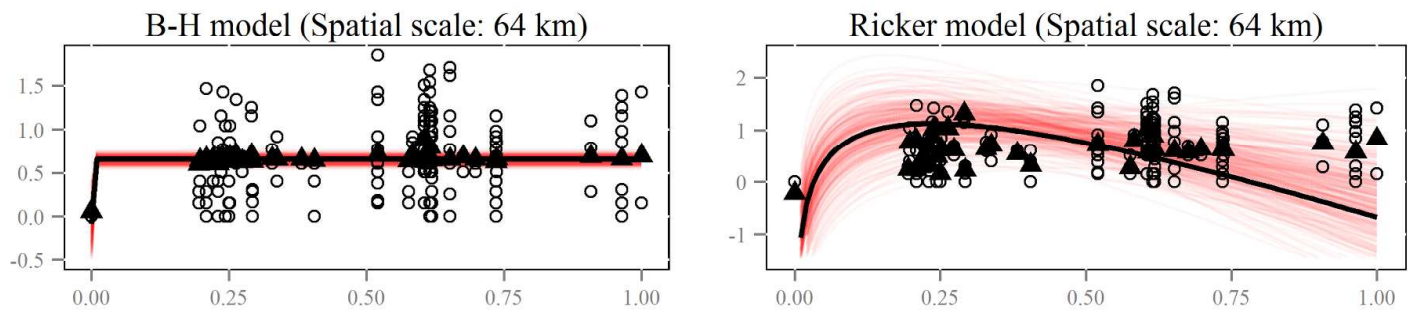

B-H model (Spatial scale: $128 \mathrm{~km})$
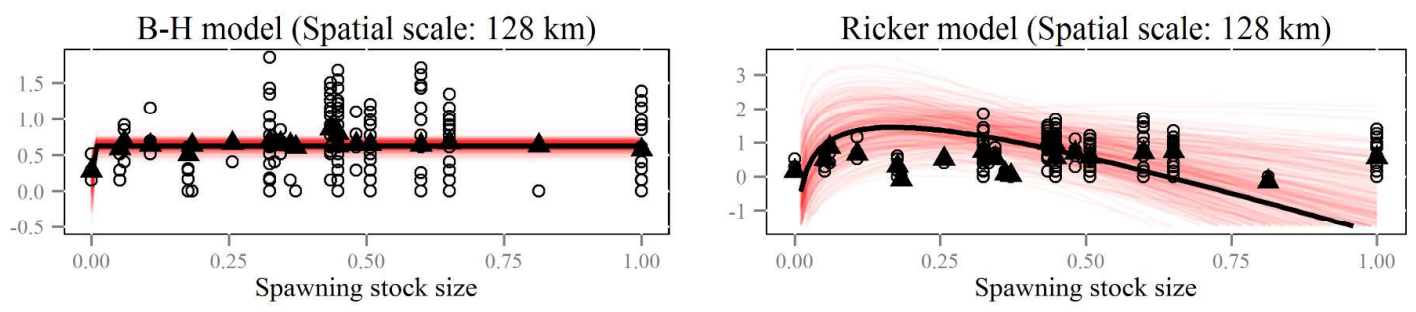
